\title{
State Medicaid Expansions and Mortality, Revisited: A Cost-Benefit Analysis
}

\section{Citation}

Sommers, Benjamin D. 2016. State Medicaid Expansions and Mortality, Revisited: A Cost-Benefit Analysis. American Journal of Health Economics. Forthcoming.

\section{Permanent link}

http://nrs.harvard.edu/urn-3:HUL.InstRepos:27305958

\section{Terms of Use}

This article was downloaded from Harvard University's DASH repository, and is made available under the terms and conditions applicable to Open Access Policy Articles, as set forth at http:// nrs.harvard.edu/urn-3:HUL.InstRepos:dash.current.terms-of-use\#OAP

\section{Share Your Story}

The Harvard community has made this article openly available.

Please share how this access benefits you. Submit a story.

\section{Accessibility}




\title{
State Medicaid Expansions and Mortality, Revisited: A Cost-Benefit Analysis
}

\author{
Benjamin D. Sommers* \\ Department of Health Policy \& Management \\ Harvard T.H. Chan School of Public Health \\ bsommers@hsph.harvard.edu
}

\begin{abstract}
Previous research found that Medicaid expansions in New York, Arizona, and Maine in the early 2000's reduced mortality. I revisit this question with improved data and methods, exploring distinct causes of death and presenting a cost-benefit analysis. Differences-in-differences analysis using a propensity-score control group shows that all-cause mortality declined by $6 \%$, with the most robust reductions for healthcare-amenable causes. HIV-related mortality (affected by the recent introduction of antiretrovirals) accounted for $20 \%$ of the effect. Mortality changes were closely linked to county-level coverage gains, with one life saved annually for every 239316 adults gaining insurance. The results imply a cost-per-life saved ranging from $\$ 327,000$ to $\$ 867,000$, which compares favorably to most estimates of the value of a statistical life.
\end{abstract}

Keywords: Medicaid, health insurance, mortality

JEL Codes: I13, I18, I38, D31

Version Date: June 1, 2016

Acknowledgments / Disclosures: This work was supported in part by grant number K02HS021291 from the Agency for Healthcare Research and Quality (AHRQ). I am grateful to Kate Baicker, Arnie Epstein, Joe Newhouse, Kosali Simon, and the participants in the health policy seminar at Yale's Institution for Social and Policy Studies for helpful suggestions. The author currently serves part-time as an advisor in the Office of the Assistant Secretary for Planning and Evaluation, at the U.S. Department of Health and Human Services (HHS). This paper does not represent the views of HHS or AHRQ.

Note: This is pre-publication print for an article accepted for publication by the American Journal of Health Economics. 


\section{INTRODUCTION}

The major expansion of Medicaid eligibility under the Affordable Care Act (ACA) - and the subsequent flexibility granted to states by the Supreme Court to opt out - has prompted a renewed debate about the value of Medicaid coverage. While evidence from the Oregon Health Insurance Experiment (OHIE) and other recent studies have demonstrated the program's value in reducing financial risk to beneficiaries and increasing access to health care services (Baicker et al., 2013; DeLeire, Dague, Leininger, Voskuil, \& Friedsam, 2013; Finkelstein et al., 2012; Sommers \& Oellerich, 2013), the literature is more ambiguous about the impact of Medicaid on health. This, in turn, has fueled significant debate about the relative economic merits of spending billions of additional public dollars on the program. With nearly 20 states still debating whether to expand Medicaid under the ACA, the relevance of these issues is clear.

In the landmark OHIE, which studied the effects of a lottery that randomly offered approximately 10,000 low-income adults the opportunity to enroll in Oregon's Medicaid program, acquiring Medicaid led to significant improvements in self-reported health and mental health, but no statistically significant changes in several physiologic measures. Meanwhile, in a much larger but non-randomized analysis of three state Medicaid expansions in the early 2000s, Sommers, Baicker, and Epstein (2012) used a differences-in-differences framework and found improved selfreported health and a significant decline in population-level mortality over a 5-year follow period for non-elderly adults, compared to four neighboring states without expansions. The OHIE results - along with several methodological concerns about the Sommers et al. paper - have left some analysts to conclude that Medicaid offers no health benefits to beneficiaries (Roy, 2013).

Here, I revisit the Medicaid expansions in three states - New York, Arizona, and Maine which extended Medicaid eligibility to a similar population of low-income adults as the OHIE and 
ACA expansions, ${ }^{1}$ with several important methodological improvements. Using restricted access microdata (1997-2007) from the Centers for Disease Control and Prevention (CDC), which captures detailed information on every death occurring the United States each year, I develop a more ideal control group for these expansion states, matching counties in those states based on preexpansion mortality trends, as well as county-level demographic and economic indicators. I also use the more detailed data to explore specific causes of death, including healthcare-amenable causes of death - which previous research suggests may be more responsive to better access to medical care (Nolte \& McKee, 2003; Sommers, Long, \& Baicker, 2014) - and deaths related to HIV, since the introduction of highly-aggressive antiretroviral therapy for HIV in the late 1990s led to well-documented declines in mortality that partially coincided with the Medicaid expansions in these states. Finally, I link these mortality data to county-level changes in the uninsured rate from before and after the Medicaid expansion, to test for the marginal impact of the coverage expansion and conduct a cost-benefit analysis of the mortality changes.

The primary findings are threefold. First, using more detailed data and a stronger identification strategy, I find robust evidence of an impact of Medicaid expansions on mortality similar to previous research. After Medicaid expansions in these three states, the population death rate for 20-64 year old adults declined by $6 \%$, or roughly 20 deaths per 100,000, when compared to adults living in demographically and economically similar counties in non-expanding states.

Second, mortality changes varied by cause of death. Declines in mortality were most robust for deaths from so-called health care amenable causes, which declined by $6.7 \%$, while

\footnotetext{
${ }^{1}$ New York expanded eligibility to childless adults with incomes up to $100 \%$ of the federal poverty level and parents with incomes up to $150 \%$ of the federal poverty level in September 2001. Arizona expanded eligibility to childless adults with incomes below $100 \%$ of the federal poverty level in November 2001 and to parents with incomes up to $200 \%$ of the federal poverty level in October 2002. Maine expanded eligibility to childless adults with incomes up to $100 \%$ of the federal poverty level in October 2002 .
} 
deaths from other causes showed a smaller decline. While results for New York (the largest state with the largest proportional expansion) drove the all-cause mortality declines, analyses excluding New York suggest that health care amenable mortality may have declined after expansions in Maine and Arizona as well. Meanwhile, HIV-related mortality was declining quite rapidly during this period, and HIV was much more prevalent at baseline in expansion states than in the control group. HIV-related mortality declines accounted for $20 \%$ of the overall mortality effect in this study. However, the relative decline in HIV-related mortality was nearly twice as large in Medicaid-expanding states as in non-expanding states, suggesting that expanded insurance worked in tandem with new antiretrovirals to produce larger health impacts.

Third, mortality changes were closely linked to county-level changes in insurance coverage, supporting the conclusion that expansion of health insurance rather than other contemporaneous changes were driving the changing death rates. A difference-in-difference-indifference (DDD) model using elderly adults produced similar findings, further supporting the expansion of insurance coverage to working age adults as the most likely causal mechanism. Point estimates suggest that for every 239 to 316 adults gaining health insurance, one death was prevented each year. Using data from the OHIE of increased per-person health care spending from acquiring Medicaid, this suggests a societal cost of \$327,000 to \$867,000 per life saved (in 2007 dollars), depending on assumptions about the deadweight loss of public financing.

The paper is organized as follows. Section II reviews the literature on the relationship between mortality and health insurance in general, and the impact of Medicaid in particular. Section III describes the data and methods. Section IV presents the results for all-cause mortality and analyses by cause of death. Section V presents additional specifications, including a DDD model with elderly adults and a model linking changes in mortality with county-level reductions in 
the uninsured rate. Section VI presents a cost-benefit analysis and concludes.

\section{PREVIOUS LITERATURE}

There is a lack of consensus in the literature about the impact of health insurance on mortality. Studies of Medicare among the elderly have found mixed results: analysis of the 1965 introduction of Medicare did not find any mortality change (Finkelstein \& McKnight, 2008), while a regression discontinuity analysis of more recent data detected a reduction in in-hospital deaths at age 65 (Card, Dobkin, \& Maestas, 2009). Longitudinal analyses of private insurance have found large unadjusted differences in survival between insured and uninsured adults, but studies differ as to whether adjustment for underlying health differences fully explain the survival gap (Black, Espin-Sanchez, French, \& Litvak, 2013; Kronick, 2009) or still leave a residual mortality benefit of insurance (Wilper et al., 2009). Most recently, an analysis of Massachusetts' 2006 health reform found a significant reduction in mortality - particularly for healthcare-amenable causes of death compared to a propensity-score defined control group (Sommers et al., 2014).

With regard to Medicaid more specifically, a large body of research demonstrates that the program improves access to care and financial risk protection, compared to being uninsured. These studies include cross-sectional analyses using state eligibility as an instrument for Medicaid coverage (Long, Coughlin, \& King, 2005), differences-in-differences analyses of Medicaid eligibility expansions (Currie \& Gruber, 1996a, 1996b), and the recent randomized trial in Oregon (Finkelstein et al., 2012). However, evidence on Medicaid's impact on health and mortality has been mixed. Currie \& Gruber (1996a, 1996b) showed that expansions of Medicaid eligibility to pregnant women and children in the 1980s led to reductions in infant mortality and children's mortality, though others (Epstein \& Newhouse, 1998; Howell, 2001) found little or no effect. In another recent paper, the initial implementation of Medicaid in the late 1960's was linked to a $40 \%$ 
individual-level reduction in infant and child mortality for non-whites (Goodman-Bacon, 2013).

Meanwhile, among adults a potentially more definitive study exists due to Oregon's fortuitous use of a lottery to randomly select low-income adults from a waitlist for the chance to enroll in Medicaid. The OHIE showed that gaining Medicaid led to significant and rapid improvements in self-reported health, major reductions in depression, and increased use of recommended services such as cancer screening and medication for diabetes. But over a mean follow-up of 18 months, there were no statistically significant changes in blood pressure, cholesterol, or glycated hemoglobin (Baicker et al., 2013; Finkelstein et al., 2012). However, these latter three measures are far from the only pathway through which health care might reduce mortality, and some have argued that OHIE was underpowered to detect changes in these measures given the relative small number of participants who had elevated blood pressure, cholesterol, or glucose at the outset (Frakt, 2013). While OHIE did examine mortality at one year, with no significant changes detected (and a point estimate corresponding to a $16 \%$ relative mortality reduction), the confidence interval was extremely wide and could not rule out very large individual-level mortality changes, with a $95 \%$ confidence interval ranging from $-82 \%$ to $+50 \%{ }^{2}$

In the absence of any randomized trial of adequate size to settle this question, the largest quasi-experimental analysis of Medicaid's impact on adult mortality comes from Sommers, Baicker, and Epstein (2012). Using population-level vital statistics and survey data, the researchers showed that large state Medicaid expansions in 2001-2002 in New York, Arizona, and Maine led to a 3.2 percentage-point decrease in the uninsured rate, gains in access to care and self-

\footnotetext{
${ }^{2}$ Finkelstein et al. (2012) used an instrumental variables analysis of the lottery for Medicaid eligibility to identify the local average treatment effect (LATE) of acquiring Medicaid. They measured a 0.0013 percentage point decrease in the likelihood of death compared to the control group, with a 95\% confidence interval of [-.0066, .0040], from a baseline mortality rate of .008 . Thus, their estimates imply a confidence interval for an individual-level mortality change of $-82 \%$ to $+50 \%$.
} 
reported health, and a mortality decline of 20 deaths per 100,000 non-elderly adults, relative to adults in neighboring states without expansions. However, there are several potential threats to the study's identification strategy. First, different demographic features and pre-expansion trends between treatment and control states may have biased the results (Kaestner, 2012). Second, the results were largely driven by New York, which has several unique features that distinguish it from other states in the original sample. For instance, New York experienced a major increase in mortality in 2001 due to the terrorist attacks of September $11^{\text {th }}$. Third, the Medicaid expansions implemented in 2001-2002 - were concurrent with the ongoing diffusion of antiretroviral medications, which led to a dramatic decline in HIV-related mortality beginning in 1996 (Duggan \& Evans, 2008; Palella et al., 2006). ${ }^{3}$ Combined with New York's high HIV rates, this raises the possibility that new medications rather than insurance may have caused the observed mortality decline. Finally, the authors' county-level mortality analysis was subject to the ecological fallacy and did not include information on insurance coverage at the individual or even county level.

Here, I explore the impact of these three states' large Medicaid expansions with an improved data source and special attention to the main threats to validity from the original analysis: the comparability of pre-expansion trends and control state demographic features, the potential biases of September $11^{\text {th }}$ and HIV antiretroviral therapy, and the lack of a direct link between insurance coverage and the observed mortality reductions. Finally, I use the estimates of deaths prevented per person insured to present a cost-benefit analysis of these state Medicaid expansions.

\section{DATA \& METHODS}

\section{III.A. Data}

\footnotetext{
${ }^{3}$ National age-adjusted HIV-related mortality for non-elderly adults peaked at 23.8 per 100,000 in 1995 and had declined to 8.8 by 1997 and 5.3 by 2007, according to CDC official statistics (www. wonder.cdc.gov).
} 
The primary data come from national vital statistics collected by the Centers for Disease Control and Prevention (CDC). The analysis by Sommers et al. (2012) used the publicly available Compressed Mortality File, which reports annual mortality rates by county age-race-sex cells. However, in the public use file, the CDC suppressed all cells with death counts between 1-5, and Sommers et al. had to impute these suppressed values for $5 \%$ of the weighted sample. These suppression rules and imputation may have introduced bias and precluded more detailed analyses by causes of death.

To address these limitations, I obtained access to the complete U.S. Vital Statistics dataset. This dataset is available only via direct application to the $\mathrm{CDC},{ }^{4}$ and contains the following information on every U.S. death occurring each year: age group, sex, race, cause of death, and county of residence. ${ }^{5}$ The CDC pairs this information with the corresponding population denominator by county, age, sex, and race (from Census data) to allow for the calculation of an annual death rate. Causes of death are based on the International Classification of Diseases Versions 9 (1997-1998) and 10 (1999-2007).

Since differential changes in the economy in expansion vs. control states may threaten the identification strategy, the mortality data were then merged with several county-year specific economic indicators reported in the Area Resource File. ${ }^{6}$ These measures were the unemployment rate (from the Bureau of Labor Statistics' local area unemployment estimates) and median income and poverty rates (from the Census Bureau's Small Area Income Poverty Estimates). In

\footnotetext{
${ }^{4} \mathrm{CDC}$ data use policies prohibit the author from directly sharing this dataset, but the application for data access is available at http://www.naphsis.org/Pages/VitalStatisticsDataResearchRequestProcess.aspx

${ }^{5}$ Location of death is based on the individual's residence. If a person dies in a county other than where they live, his/her death is counted in mortality statistics for their home county.

${ }^{6}$ Interestingly, it is unclear what direction the potential bias would be from differential economic changes. While numerous studies document a major detrimental effect of lower socioeconomic status on survival, others have found that mortality decreases during recessions (Ruhm, 2000, 2005). More recent research suggests that adjusting for unemployment as well as poverty rates and median income may be necessary to fully capture macroeconomic influences on mortality (Gordon \& Sommers, 2015).
} 
addition, I obtained county-level measures of the uninsured rate among the 19-64 year-old age group from the Census Bureau's Small Area Health Insurance Estimates.

\section{III.B. Methods and Control Group}

The study design was a differences-in-differences analysis comparing annual mortality in county race-sex-age group cells in three expansion states - New York, Arizona, and Maine - to a control group of counties without Medicaid expansions. The control group was created by matching to the subset of U.S. counties that most resembled the counties in the expansion states based on pre-expansion mortality trends, baseline demographic features, and economic conditions. The study period was 1997-2007, with the pre-expansion baseline period defined as 1997-2000, and 2001 omitted from the sample to avoid any bias from the attacks of September 11th. ${ }^{7}$ The approach of using a propensity-score based control group of counties is similar to Sommers et al.'s 2014 analysis of Massachusetts' health reform. It resembles the synthetic control group method (Abadie, Diamond, \& Hainmueller, 2012) by matching on pre-intervention trends in the outcome, but it additionally incorporates information on key covariates that are important predictors of the outcome and that differ significantly across counties. The tradeoff of adding additional elements for matching is that the precision of the match for any one dimension may decrease as other factors are used in the propensity match. Thus, pre-expansion trend testing and placebo testing are still critical for assessing the identifying assumption.

The propensity score model was fit using the following county-level logistic regression for the whole U.S. in the pre-expansion period, weighted by each county's population size:

\footnotetext{
${ }^{7}$ The time frame differs slightly here from Sommers et al. (2012). In that paper, the sample was limited to 5 years before and after each state's expansion, which means that the study period was 1997-2006 for New York and Arizona, and 1998-2007 for Maine. Here, I use the full overlapping time period to be consistent across all states (1997-2007), with year fixed effects to capture any national mortality trends. The first full year of coverage after each expansion is considered the first post-expansion year.
} 
(1) ExpansionCounty E $_{c}=\beta_{0}+\beta_{1}$ UnemploymentRate $_{c}+\beta_{2}$ Poverty Rate $_{c}$

$$
\begin{aligned}
& +\beta_{3} \text { MedianIncome }_{c}+\beta_{4} \mathbf{X}_{\mathbf{c}}+\beta_{5} \text { MortalityRate97 }_{c}+\beta_{6} \text { MortalityRate9 }_{c} \\
& +\beta_{7} \text { MortalityRate99 }_{c}+\beta_{8} \text { MortalityRate00 } \\
& +\varepsilon_{c}
\end{aligned}
$$

where $c$ indexes the county. ExpansionCounty was a binary variable equal to 1 for counties in New York, Arizona, and Maine, and 0 otherwise. $\mathbf{X}_{\mathbf{c}}$ is a vector of demographic traits (percentages of the county's population in each age group, race/ethnicity, and sex), based on the population of adults ages 20-64. ${ }^{8}$ All economic and demographic variables (including the county annual employment rate, poverty rate, and median household income) were averaged over the 1997-2000 pre-expansion period. Coefficients $\beta_{5}$ through $\beta_{8}$ captured the annual mortality pattern (MortalityRate97 for the year 1997, for instance) for this same period. Then the model was used to generate predicted values (propensity scores) for each county, indicating its similarity to the expansion counties' overall population and mortality pattern over time.

In traditional propensity score matching, these propensity scores are then used to select specific matches to serve as controls for each treatment county. However, the distinctive nature of the CDC mortality dataset introduces several challenges with this approach: the counties have widely different population sizes that have to be taken into account in the final regression models to produce meaningful population estimates, and the overall number of counties in the treatment states is small - just 93 overall, which may lead to a lack of power particularly for subgroup analyses. Thus, following previous work analyzing this dataset (Sommers et al., 2014), I use the propensity score to describe a composite synthetic control group defined as the quartile of counties (weighted by population size) with the highest propensity scores - i.e. those most

\footnotetext{
${ }^{8} 19$ year olds are classified in the mortality data as part of the 15-19 year-old age group, which is why the sample for working age adults for this analysis begins at age 20 .
} 
closely resembling the overall population of the three expansion states. This approach resulted in control counties being identified in all remaining 47 states but not the District of Columbia, yielding a final sample containing 50 state clusters. As a sensitivity analysis, I also tested more traditional propensity score matching approaches, using 5:1, 3:1, and 2:1 propensity score matches (without replacement) for each expansion county, incorporating a caliper of 0.2 times the standard deviation of the logit propensity score to confirm reasonable matches (Austin, 2011). These analyses produce similar findings as the main model.

Appendix Table A.1 shows the results from the logistic regression model for Equation 1. The strongest county-level predictors of expansion status (as measured by the test statistic) were the age distribution (with expansion counties having an older population on average than the nation as a whole) and poverty rate (with expansion counties having a higher poverty rate on average). Other significant predictors were a higher proportion of women, fewer Latinos, and lower mortality in 1998 and 2000. Mortality rates for 1997 and 1999 are non-significant due to multicolinearity; in models only considering a single year mortality rate at a time, each of the four years are significant predictors $(\mathrm{p}<0.05)$ in Equation 1.

To determine whether this approach yielded a control group with similar pre-expansion mortality trends, I first tested for differential linear trends for the years 1997-2000 in the control states versus the expansion states. I then conducted a falsification test for any divergence in mortality trends in 2000 (the last full year before the first expansions began), using only the 1996-2000 pre-expansion data and treating 2000 as a placebo expansion year. The results of these analyses, reported in Section IV, support the identifying assumption of similar preexpansion mortality trends. Equation 2 describes the linear trend testing, and Equation 3 describes the placebo test, both of which were analyzed using the pre-expansion data (1997- 
2000) and weighted by population size:

$$
\begin{gathered}
\text { MortalityRate }_{i j k c t}=\beta_{0}+\beta_{1} \mathbf{X}_{\mathbf{i j k}}+\beta_{2} \text { County-Level Factors }_{\mathbf{c t}}+\beta_{3} \text { Time Trend }_{t} \\
+\beta_{4} \text { Expansion State }_{s}{ }^{*} \text { Time Trend }_{t}+\Omega \text { County }_{c}+\varepsilon_{i j k t}
\end{gathered}
$$

where $i$ indexed age, $j$ race, $k$ sex, $c$ county, $s$ state, and $t$ year. The dependent variable is the mortality rate per 100,000 adults in each age-race-sex-county-year observation. $\mathbf{X}_{\mathrm{ijk}}$ was a vector of demographic traits (age group, race, and sex). County-Level Factors included countyyear-specific poverty rate, median income (in 2007 inflation-adjusted dollars), unemployment rate, and percentage of the population that is Latino. ${ }^{9} \Omega$ is a vector of county fixed effects. $\beta_{3}$ is a linear time trend, and $\beta_{4}$ measures any differential time trend for the expansion states, compared to the control group.

$$
\begin{aligned}
& \text { MortalityRate }_{i j k c t}=\beta_{0}+\beta_{1} \mathbf{X}_{\mathbf{i j k}}+\beta_{2} \text { County-Level Factors }_{\mathbf{c t}} \\
& +\beta_{3} \text { ExpansionState }_{s} * Y 2000_{s t}+\mu \text { Year }_{t}+\Omega \text { County }_{c}+\varepsilon_{i j k c t}
\end{aligned}
$$

Equation 3, which represents the placebo test for a differential mortality effect in the last pre-expansion year, replaces the linear time trend with $\mu$, a vector of year fixed effects. Then $\beta_{3}$ captures the effect of living in an expansion state in the year 2000, the last year before any of the state Medicaid expansions. The remaining terms are defined as in Equation 2. The regression used Huber-White robust standard errors clustered at the state level $(\mathrm{n}=50)$.

\section{III.C. Analyses of All-Cause Mortality}

The primary outcome was all-cause mortality, expressed as deaths per 100,000 adults. The unit of analysis was the year-specific age-sex-race cell within each county. Equation 4

\footnotetext{
${ }^{9}$ The CDC did not include ethnicity in the mortality data until 1999, and some death certificates after 1999 were still missing this information. I use the year-specific county-wide percentage of the population that is Latino, from the Area Resource File, to allow for the full sample to be included in the analysis. Thus, while race is directly-adjusted for at the individual level as part of vector $\mathrm{X}_{\mathrm{ijk}}$, Latino ethnicity is adjusted for at the county level.
} 
shows the primary regression model:

$$
\begin{aligned}
& \text { MortalityRate }_{i j k c t}=\beta_{0}+\beta_{1} \mathbf{X}_{\mathbf{i j k}}+\beta_{2} \text { County-Level Factors }_{\mathbf{c t}} \\
& +\beta_{3} \text { ExpansionState }_{s} * \text { Post-Expansion }_{t}+\mu \text { Year }_{t} \\
& +\Omega \text { County }_{c}+\varepsilon_{i j k c t}
\end{aligned}
$$

As above, $i$ indexed age, $j$ race, $k$ sex, $c$ county, $s$ state, and $t$ year. The dependent variable is mortality per 100,000 adults in each age-race-sex-county-year observation. $\mathbf{X}_{\mathbf{i j k}}$ was a vector of demographic traits (age group, race, and sex). County-Level Factors included countyyear-specific poverty rate, median income (in 2007 dollars), unemployment rate, and Latino percentage of the population. $\beta_{3}$ is the coefficient of interest, capturing the effect of being in an expansion state $($ ExpansionState $=1)$ after Medicaid expansion $($ Post-Expansion $=1)$. The direct effects of the post-expansion period and being in an expansion state are respectively captured by $\mu$, a vector of year fixed effects, and $\Omega$, a vector of county fixed effects. Robust standard errors were clustered by state $(\mathrm{n}=50)$ (Bertrand, Duflo, \& Mullainathan, 2004).

The primary regressions used linear models, but I also tested the robustness of the results using a generalized linear model (GLM) with a negative binomial distribution and log-link, which reports relative changes in mortality. The GLM regression equation was the same as the linear model, except the dependent variable was the number of deaths, with population size as the exposure variable. The GLM model also replaced county fixed effects with state fixed effects because negative binomial models do not perform well with numerous fixed effects. ${ }^{10}$

\section{III.D. Analyses by Causes of Death}

I conducted two additional sets of analyses, analogous to the model in Equation 4, but with

\footnotetext{
${ }^{10}$ See additional discussion of this issue in (Greene, 2005): 113-218.
} 
different disease-specific mortality rates. First, following previous work used in international comparisons of mortality (Nolte \& McKee, 2008; Nolte \& McKee, 2003) and in the analysis of Massachusetts' health reform (Sommers et al., 2014), I identified deaths due to so-called "healthcare-amenable" causes, including cardiovascular disease, infections, cancer, diabetes, kidney disease, and other conditions thought to be more responsive to timely medical care. The notion of health care amenable causes of death has been widely used to assess health system performance and has been embraced by the World Health Organization (2000) as a measure of health care quality. Major causes excluded from this definition include accidental deaths, suicides, and homicides. There has been suggestive evidence that insurance status can reduce mortality even from some of the latter conditions - for instance, in-hospital mortality may be as much as $40 \%$ higher for trauma victims without health insurance compared to insured patients (Doyle, 2005). However the majority of trauma deaths occur before hospital admission, as is the case for homicides, suggesting that health insurance has limited ability to impact these conditions at the population level compared to other causes listed above. ${ }^{11}$ Meanwhile, the OHIE showed that the acquisition of Medicaid significantly reduces depression rates (Baicker et al., 2013), raising the possibility that coverage might also reduce suicide rates. While some trials of specific cognitive interventions have been shown to reduce recurrent suicide attempts (Brown et al., 2005), the most common medical intervention for depression (antidepressant use) has not been shown to reduce suicides in randomized trials (Fergusson et al., 2005), and the overall evidence base is mixed as to whether medical care reduces the risk of self-harm (Hawton et al., 2000). Thus, it is reasonable to

\footnotetext{
${ }^{11}$ According to my analysis of CDC mortality data of non-elderly adults from 1999-2014 (available at http://wonder.cdc.gov/ucd-icd10.html), fewer than $20 \%$ of transportation-related fatalities occur while receiving hospital care; the majority die before arrival to the hospital, and another 19\% die in the Emergency Department. Similarly, for homicides, only $17 \%$ occur during a hospital inpatient stay.
} 
assume that any mortality effects mediated by insurance coverage should be larger for healthcareamenable causes than for these other causes of death.

A second set of analyses examined deaths due to HIV and AIDS, and conversely analyzed mortality from all causes other than HIV. As discussed earlier, the introduction of highly aggressive anti-retroviral therapy (HAART) in the late 1990s and early 2000s led to major reductions in HIV-related mortality (Palella et al., 2006), and this trend was concurrent with these Medicaid expansions. Separating out this cause of death and looking at the relative declines in mortality between expansion and control states can shed light on the extent to which the all-cause mortality changes are attributable to HIV alone, and also whether Medicaid expansion facilitated the mortality reductions due to HAART among those with HIV.

\section{RESULTS}

\section{IV.A. Descriptive Statistics and Control Group}

Table 1 summarizes the baseline characteristics for the three expansion states compared to a) the propensity-defined control group; b) the four neighboring states used as the original control group from Sommers et al. 2012 (Pennsylvania, Nevada, New Mexico, and New Hampshire); and c) the full U.S. sample outside of the expansion states. Given the large numbers of counties, many of these differences are statistically significant, but here I focus on the absolute magnitude of those differences and the standardized differences of the mean as more relevant measures of whether the groups are reasonably comparable. ${ }^{12}$

Overall, standardized differences between the expansion states and propensity score group (ranging from 0.01 to 0.28 ) were smaller than the differences between the expansion states

\footnotetext{
${ }^{12}$ For instance, the percentage of adults in the $34-45$ age group was $27.1 \%$ in the expansion states and $27.5 \%$ in the propensity score control group, $\mathrm{p}=0.03$, but in the context of a differences-in-differences analysis which also adjusts directly for age, this 0.4 percentage-point difference is highly unlikely to bias the results.
} 
and the neighboring states (ranging between 0.23 and 0.68 ) for all but one of the 14 estimates.

Thus, for nearly all measures, the propensity score control group resembled the expansion states more closely than does the neighboring state control group that has been used in previous research. While these differences were smaller for the propensity score control group, several standardized differences still exceeded the threshold of $10 \%$ that is one commonly-used goal for propensity score analyses (Austin, 2011). However, note that while I use propensity scores here to improve the comparability of the control group, the study's causal identification still comes from differences-in-differences analysis, for which there is no precondition of comparability of covariates. Rather, the identifying assumption is still that in the absence of the Medicaid expansion, mortality trends would have been similar in the expansion and control states. The following section presents results of the tests for pre-expansion mortality trends.

\section{IV.B. Pre-expansion Trends and Placebo Tests}

Figure 1 depicts mortality changes in the Medicaid expansion states and the propensityscore control group (hereafter referred to simply as "the control group") for all-cause mortality, deaths due to healthcare-amenable causes, and deaths from other causes. The pre-expansion mortality curves followed similar trajectories prior to 2001, when the expansions began. In the post-expansion period, mortality in the expansion states fell while it rose slightly in control states. Healthcare-amenable deaths show a post-2001 decline in expansion states, but not in control states. For non-amenable (or, to be more accurate, "less amenable") causes of death, mortality rose slightly in control states after 2001 and was relatively flat in the expansion states. ${ }^{13}$

Table 2 presents the regression results for tests of parallel trends and the placebo test for

\footnotetext{
${ }^{13}$ The impact of the terrorist attacks of September $11^{\text {th }}$ are visible in the non-amenable causes of death, with a slight uptick in this outcome for expansion states in 2001, before mortality returns to its 2000 level the following year.
} 
the year 2000, comparing expansion states and the control group. In the linear trend analysis, the coefficient on Expansion State*Time Trend was statistically non-significant and close to zero ( 0.69 per 100,000 per year, $p=0.56)$. In the placebo differences-in-differences model, the coefficient on Expansion State ${ }^{*}$ Year2000 was also small and non-significant (1.80 per 100,000, $\mathrm{p}=0.42$ ). Thus both the time trend and placebo analyses show that the propensity score approach yielded a good match in baseline trend, consistent with the visual evidence in Figure 1. The negative binomial GLM model produced similarly reassuring null results. While these results should not be surprising, given that the control group was selected in part based on the preexpansion mortality rates, it is nonetheless useful to verify this as a necessary condition for the study's identification strategy.

\section{IV.C. Changes in All-Cause Mortality}

Table 3 presents the differences-in-differences results for all-cause mortality, in linear and negative binomial GLM models. In both models, Medicaid expansions led to a significant decline in all-cause mortality, equivalent to 19.1 fewer deaths per 100,000 in the linear model and a relative decline of $6.0 \%$ in the negative binomial model. These two results are nearly identical in comparison to the baseline mortality rate of 318 per 100,000 . Other significant predictors of mortality were older age, black race, male sex, and higher poverty / lower median income.

\section{IV.D. Analyses by Cause of Death and HIV}

Table 4 presents differences-in-differences estimates for several types of mortality based on cause of death. Mortality reductions were significant $(\mathrm{p} \leq 0.01)$ for healthcare-amenable deaths, with a linear estimate of -12.0 per 100,000 and the negative binomial model showing a $6.7 \%$ reduction after the Medicaid expansion. Deaths from causes less amenable to health care also 
declined, though the effects were not significant at $\mathrm{p} \leq 0.05(\mathrm{p}=0.068$ in the linear model, $\mathrm{p}=0.063$ in GLM). While generally supportive of the hypothesis that healthcare-amenable diagnoses should be more highly impacted than other causes of death, the estimates for non-amenable causes are fairly imprecise and contain $95 \%$ confidence intervals extending well above and below the $6.0 \%$ relative decline in all-cause mortality.

Figure 2 plots HIV-specific mortality during the study period for the expansion states and the control group. HIV-related mortality in the expansion states was nearly three-fold higher than in the control states in the baseline period, and was already declining in both treatment and control states prior to the Medicaid expansions. However, the decline in control states was gradual after 2002, while the decline continued to accelerate in the expansion states, markedly narrowing the gap compared to the control states.

The regression results in Table 4 shows that HIV-related deaths were indeed declining more rapidly in the treatment states after Medicaid expansion, by 3.8 deaths per 100,000 in the linear model. However, the linear model is biased by the difference in absolute risk of HIV at baseline, and pre-expansion trends show a significant divergence in HIV mortality (coefficient on Expansion State $*$ Time Trend $=-0.9, \mathrm{p}<0.001)$. This bias in the absolute HIV-mortality reduction does not require that there was any faster diffusion of antiretrovirals in expansion states than nonexpansion states; the large difference in baseline prevalence of HIV alone creates this bias in the linear differences-in-differences model, even if the relative mortality reduction from these treatments was identical across states. The linear estimate in Table 4 suggests that roughly $20 \%$ (3.8/19.1) of the all-cause mortality decline after Medicaid expansions were attributable to HIV. Even after removing HIV deaths from the analysis, mortality from all other causes still experienced a highly significant decline in both models. The most cautious reckoning of this result is to assume 
that the full HIV effect was solely due to the introduction of antiretroviral medications and had nothing to do with Medicaid expansion.

However, this assumption is likely inaccurate, as insurance coverage may have an interactive effect with new medical technology - especially for expensive treatments such as antiretrovirals. While federals funding through the Ryan White Program provides access to HIVrelated treatment to many low-income Americans, it does not provide comprehensive insurance and is subject to block grants to states and localities that may limit its reach (Kaiser, 2013). This suggests a significant potential role for Medicaid to expand access to HIV treatment, consistent with one prior instrumental variables analysis of insurance coverage in the early years of antiretroviral medications, which detected a 70-85\% reduction in mortality for HIV-positive individuals obtaining Medicaid (Goldman et al., 2001).

For measuring whether Medicaid expansion facilitated the mortality reductions from antiretroviral therapy, the negative binomial GLM approach is preferable to the linear model, since it measures the differential relative change in HIV mortality and is not biased by higher baseline absolute HIV mortality in the expansion states. In the GLM model, there was no significant divergence in pre-expansion trends $(-0.013, \mathrm{p}=0.13)$, and the differences-in-differences estimate indicates a $13.6 \%$ relative reduction in HIV mortality due to the Medicaid expansion. The unadjusted mortality statistics for HIV tell a similar story: the pre vs. post-expansion HIV death rate went down by $16 \%$ in the control group, while it decreased by $34 \%$ in expansion states. This suggests that Medicaid expansion facilitated the impact of antiretrovirals in the treatment of HIV, consistent with Goldman et al.'s 2001 findings.

As an additional analysis to probe these results, I created an HIV-specific comparison group, using the same matching approach described earlier, but with a focus on HIV-related 
mortality in the pre-expansion period. These results are presented in the last row of Table 4, which shows a similar general pattern as in the primary analysis - a roughly $15 \%$ relative reduction in HIV mortality due to the Medicaid expansion (or 2.6 deaths per 100,000).

However, even within this HIV-specific control group, there was evidence of divergence in the pre-expansion HIV-mortality trends $(-1.0, \mathrm{p}<0.001)$. Narrowing the control group to the top decile of propensity-matched counties produced similar divergence. The difficulty in finding a comparable control group for this outcome points to how atypical the expansion states (New York in particular) were in terms of their high HIV rates.

Finally, due to the differential trends in HIV mortality in our expansion and control group, I also tested the effect of repeating the entire process of constructing the control group using non-HIV mortality only. These results, presented in Appendix Table A.2, show very similar results as the primary model - with reductions in all-cause mortality of -17.2 per 100,000 $(\mathrm{p}=0.01)$ in the linear model and $-5.6 \%(\mathrm{p}=0.01)$ in the GLM model, and for non-HIV mortality of -13.7 per 100,000 in the linear model $(p=0.02)$ and $-4.0 \%$ in the GLM model $(p=0.02)$. Thus, whether or not one includes HIV deaths in the matching process for the control group does not substantially change the overall findings. The use of microdata with information on specific causes of death therefore lets us confidently exclude one important threat to validity - that HIVrelated changes were driving the findings for all-cause mortality after expansion.

\section{IV.E. Robustness Checks and Omitting New York from the Sample}

Appendix Table A.2 presents several additional robustness checks. Pooling the data into a collapsed pre- and post-period to avoid any potential serial autocorrelation (Bertrand et al., 2004) produces nearly identical results, as does collapsing the county data into 500 state-year cells. Adding the year 2001 back into the sample also has minimal impact on the results. An interrupted 
times-series model, in which the expansion is modeled as a change in slope in the mortality rate instead of an average change in level, shows that mortality gains grew over time: each additional post-expansion year led to a decline in the death rate of 4.3 per $100,000(p<0.001)$. Including additional years of data through 2010 also supports the conclusion that mortality gains grew over time. ${ }^{14}$ Adding data from 2008-2010 increases the estimated change in all-cause mortality from 19.1 per 100,000 to 22.5 per 100,000 , and linear coefficients for other causes of death listed in Table 4 show similar changes that are 15-20\% larger in magnitude than in the primary model. Using traditional "nearest neighbor" propensity score matching (5:1, 3:1, and 2:1) produces slightly smaller but highly significant declines in mortality due to the Medicaid expansions (-13.5 to -14.7 per 100,000 , or $-4.4 \%$ to $-6.2 \%$ in GLM), compared to our baseline model that used as the control group the highest quartile of counties based on propensity scores.

State expansion effects may be heterogeneous, given that Medicaid programs vary considerably across states in many domains (Weil, 2003), including provider payment rates, provider adequacy, patient cost-sharing, covered benefits, and use of managed care - which has been the exclusive delivery model used in Arizona's Medicaid program since its inception in 1982 (McCall, 1997). New York's population also predominates in the full sample. Accordingly, I tested the impact of excluding New York from our sample, using a propensity-matched control group for Maine and Arizona constructed analogously to the overall control group. Appendix Table A.3 presents these results. The estimated mortality declines in both linear and GLM models were much smaller than for the overall sample. With a more refined control group and richer data on cause of death, I find a significant decline of $2.7 \%$ in healthcare-amenable deaths in these two

\footnotetext{
${ }^{14}$ While data beyond 2010 are available, this crosses into the period of the implementation of the Affordable Care Act, which expanded coverage to young adults on their parents' plans beginning in September 2010, and six states began their ACA Medicaid expansions between 2011-2012 under the law's "early expansion" option.
} 
states in the negative binomial model. However, this finding is contingent on the functional form and is not significant in the linear model. While suggestive of a potential impact of the Medicaid expansion in these two states, mortality changes in these states nonetheless appear smaller than those in New York.

Numerous policy differences exist between Medicaid programs across states. It is possible that some of these differences help explain the larger and more robust mortality changes detected in New York. For instance, New York's physician capacity, measured per 100,000 residents, far exceeded that of Arizona and Maine (385 per vs. 204 and 246, respectively, as of the year 2000), and this may serve as an important facilitator of population health effects in a coverage expansion. ${ }^{15}$ New York's Medicaid program during this period was also particularly generous with one 50-state analysis concluding that New York's Medicaid program was the most comprehensive in the nation in terms of benefits and cost-sharing (Arellano \& Wolfe, 2007).

While it is possible that the New York Medicaid expansion produced larger mortality changes because of differences in program features, another likely contributor is that the much smaller populations in Maine and Arizona, combined with smaller relative expansions, limited the power to detect a population-level effect on mortality. Enrollment statistics for the Medicaid expansion programs from winter 2005 indicate that New York had enrolled over 460,000 individuals in its expansion (Artiga \& Mann, 2005) - approximately 4\% of its non-elderly adult population, based on data from the 2005 Current Population Survey. By contrast, Maine had enrolled just under 24,000 and Arizona 13,000, which combined to represent just $0.9 \%$ of the nonelderly adult population in those two states. Thus, the expansion in New York was more than 12

\footnotetext{
${ }^{15}$ While New York has below-average physician participation rates in Medicaid, this disparity is far outweighed by New York's overall greater number of physicians. $62 \%$ of New York physicians accept Medicaid, compared to $74 \%$ in Maine and 78.5\% in Arizona (Decker, 2013). Applying these percentages to physician capacities, New York still has 240 Medicaid-participating physicians per 100,000, compared to 160 in Arizona and 182 in Maine.
} 
times as large in absolute terms and 4 times as large in relative terms than the expansions in the other two states put together. These dramatic differences in population size and expansion impact may explain why results for the two smaller states are much more equivocal.

\section{ALTERNATIVE SPECIFICATIONS}

\section{V.A. DDD Model Using Elderly Adults as Additional Control}

One natural test of whether Medicaid expansion was in fact the underlying cause for the observed mortality decline comes from a comparison to elderly adults. Adults 65 and over are generally excluded from Medicaid eligibility expansions, and baseline coverage rates are in the range of $98-99 \%$ due to Medicare (DeNavas-Walt, Proctor, \& Smith, 2011). However, many potential state-specific mortality changes related to improvements in medical technology, the environment, or epidemiology of disease should be filtered out by the DDD approach.

The model was a standard DDD regression, described in Equation 5:

$$
\begin{aligned}
\text { Death }_{i j k l t}=\beta_{0} & +\beta \mathbf{X}_{\mathbf{i j k}}+\beta_{1} \text { Post-Expansion }_{t} * \text { Non-Elderly }_{i} \\
& +\beta_{2} \text { Non-Elderly }_{i} * \text { ExpansionState }_{s}+\beta_{3} \text { ExpansionState }_{s} * \text { Post-Expansion }_{t} \\
& +\beta_{4} \text { ExpansionState }_{s} * \text { Post-Expansion }_{t} * \text { Non-Elderly }_{i} \\
& +\beta_{5} \text { County-Level Factors }_{\mathbf{c t}}+\mu \text { Year }_{t}+\Omega \text { State }_{s}+\varepsilon_{i j k l s t}
\end{aligned}
$$

Direct effects for age are captured by the vector $\mathbf{X}$ (which includes age group, race, and sex), while direct effects of the post-expansion period and being in an expansion state are captured by, year fixed effects $(\mu)$, and state fixed effects $(\Omega)$. County-level factors are as in Equation 4 . The full set of interaction terms for age, time period, and expansion state are included. $\beta_{4}$ is the coefficient of interest, capturing the effect of being in an expansion state after expansion for nonelderly adults, relative to adults 65 and older. Given very different baseline death rates for the elderly vs. non-elderly (Appendix Figure A.1), this analysis uses the negative binomial GLM. 
Appendix Figure A.1 shows the mortality trends for elderly adults in expansion and control states, which appear similar before and after the Medicaid expansions. Table 5 presents the regression results. All-cause mortality changed by $-1.5 \%$ among elderly adults after Medicaid expansion in the treatment states, while the DDD estimate for non-elderly adults was a $-4.8 \%$ decline after the expansion, with both coefficients significant at $\mathrm{p}<0.10$. This corresponds to an expansion effect specific to non-elderly adults 4 times larger than for elderly adults $(6.3 \%$ vs. $1.5 \%$ ). By cause of death, the DDD estimate for healthcare-amenable mortality among nonelderly adults was $-6.2 \%(p<0.001)$, with no direct effect on elderly adults, and neither age group experienced a significant decline in non-amenable causes of death after expansion.

\section{V.B. Mortality and County-Level Changes in the Uninsured Rate}

In this section, I test directly whether county-level estimates of health insurance coverage in these expansion states were tied to the observed mortality changes. This approach is similar to several studies of Massachusetts' health reform (Miller, 2012; Sommers et al., 2014) and a recent working paper on the Affordable Care Act (Courtemanche, Marton, Ukert, Yelowitz, \& Zapata, 2016), which rely on local variation in insurance coverage rates as an additional means of identifying the effect of coverage expansion. This analysis used county-level data on the percentage of adults 19-64 who are uninsured, from the U.S. Census Bureau's Small Area Health Insurance Estimates (SAHIE). SAHIE estimates are based on microdata from the Current Population Survey, combined with data from the 2000 Census and administrative data from the Internal Revenue Service, the Supplemental Nutritional Assistance Program, and Medicaid. ${ }^{16}$ SAHIE data are available for 2000-2001 (the pilot years of the program), and subsequently from

\footnotetext{
${ }^{16}$ For more detail, see "Small Area Health Insurance Estimates," U.S. Census Bureau, available at: https://www.census.gov/did/www/sahie/methods/20052007/index.html
} 
2005 onwards, which means data are not available for multiple pre- and post-expansion years in the study period. I present several analyses to account for these data limitations. ${ }^{17}$

The first approach simply stratified the original sample into two sets of counties - high uninsured counties and low-uninsured counties, using the 2000 population-weighted median uninsured rate in the expansion states. The results in Table 6 (Model 1) indicate that counties with high uninsured rates prior to Medicaid expansion experienced much larger mortality reductions (29.4 per 100,000), compared to counties with low uninsured rates $(-7.7$ per 100,000). The second approach follows that used by Miller (2012) in her analysis of Massachusetts, in which she used the pre-expansion county uninsured rate interacted with a post-expansion indicator as the independent variable of interest. The results (Model 2 in Table 6) show that mortality declines varied significantly with the pre-expansion uninsured rate, with a coefficient of -99.4. This corresponds to a mortality decline of 9.94 per 100,000 for each additional $10 \%$ increment in the pre-expansion county-level uninsured rate.

The previous two models have the advantage of measuring coverage exogenously, by using only pre-expansion data to identify counties with larger potential gains in coverage. However, for a cost-benefit analysis, it is necessary to measure the mortality change per additional person insured. For this analysis, I estimated the following linear model using those years for which SAHIE data are available (2000, 2005-2007), replacing the binary differences-in-differences indicator with a parameterized measure of coverage gains from the Medicaid expansion:

$$
\begin{aligned}
& \text { Mortality Rate }_{i j k t}=\beta_{0}+\beta_{1} \mathbf{X}_{\mathbf{i j k}}+\beta_{2} \text { County-Level Factors }_{\mathbf{c t}}+\beta_{3} \Delta \text { Coverage }_{c t} \\
& +\beta_{4} \text { ExpansionState }_{s}{ }^{*} \text { Coverage }_{c t}+\mu \text { Year }_{t}+\Omega \text { County }_{c}+\varepsilon_{i j k c t}
\end{aligned}
$$

\footnotetext{
${ }^{17}$ In addition, the baseline 2000 SAHIE data were for adults ages 19 and older. To make these estimates comparable to the 2005-2007 figures (ages 19-64), I subtracted out the elderly population of each county, assuming that the elderly coverage rate was $100 \%$.
} 
$\Delta$ Coverage represents the change in county-level insured rate compared to $2000 . \beta_{4}$ is the coefficient of interest, measuring the impact of coverage gains in Medicaid expansion states. All other variables are defined as in Equation 4. I also considered a model limiting the data to a single pre- and post-expansion data point (2000 and 2007) for a balanced panel, as well as models with the addition of the original ExpansionState * Post interaction term. This latter approach allows for changes in mortality in expansion states not mediated by changes in the county-level coverage rates, given previous findings of spillover effects of coverage expansion even on those who already have health insurance (Pauly \& Pagan, 2007). ${ }^{18}$

Table 6 presents these results. In all models, county-level coverage gains led to significant mortality declines, with point estimates ranging from -316 to -419 . $\Delta$ Coverage is reported as a fraction from -1.0 to 1.0 , so these coefficients indicate that each percentage point of coverage led to 3.16-4.19 fewer deaths per 100,000. Alternatively, this suggests that the expansions needed to cover between 239 and 316 people to prevent one death per year, the so-called number-needed-totreat $(\mathrm{NNT}){ }^{19}$ We can use this parameter to translate the observed population level mortality changes into an individual-level risk reduction in mortality due to gaining coverage, with the following relationship: ${ }^{20}$

NNT * baseline mortality $*$ individual risk reduction $=1$ death per 100,000.

\footnotetext{
${ }^{18}$ An alternative approach would be to use Medicaid expansion as an instrument for county-level changes in the uninsured rate. This approach yields a larger reduction in mortality linked to coverage gains, with a coefficient of $1127(\mathrm{p}=0.04)$. However, the direct effect of ExpansionState ${ }^{*}$ Post in Table 6 remains significant in models containing county-level coverage changes, which suggests that the SAHIE county-level estimates of coverage gains do not explain the full mortality effect. This may be due to a combination of measurement error in the SAHIE and spillover effects of expansions that affect mortality through channels other than increasing coverage. In any event, these results suggest that the exclusion restriction does not hold.

${ }^{19}$ A coefficient of -419 means -4.19 fewer deaths per 100,000 for a percentage point of coverage. NNT $=1000$ covered per 100,000 / 4.19 deaths prevented per $100,000=239$.

${ }^{20}$ This calculation makes the assumption that all mortality gains accrue to those individuals who gained coverage, without any spillover effects on other people in the state. If there are any spillover effects on population mortality, this calculation will overstate the individual-level risk reduction associated with acquiring health insurance.
} 
Using a NNT of roughly 300 , this leaves two degrees of freedom: the baseline mortality rate for those gaining insurance, and the individual-level risk reduction of coverage. Neither is observed directly in the mortality dataset, but one can make reasonable inferences for the former. The baseline population-wide mortality rate in expansion states was 318/100,000. But the mortality rate for uninsured adults - and in particular for uninsured adults living near or below the federal poverty level - is significantly higher. The relative risk of death among poor adults ages 19-64, compared to the general population, has been estimated to be 1.75 (Galea, Tracy, Hoggatt, Dimaggio, \& Karpati, 2011). Even after controlling for income, sex, and age, the uninsured still have higher mortality rates, with a relative risk estimated by Kronick (2009) to be 1.25 . Putting these two hazard ratios together with the baseline mortality rate implies that low-income uninsured adults in these states had a mortality rate of roughly 700 per 100,000 . If we assume that the mortality rate for those who signed up for Medicaid was equal to those who did not sign up for Medicaid, this implies an individual-level mortality reduction of $48 \%$.

However, previous research has demonstrated that poor health itself is a strong predictor of Medicaid take-up, conditional on eligibility (Kenney, Lynch, Haley, \& Huntress, 2012). This suggests that baseline mortality among those who actually enrolled in these states' Medicaid expansions was likely significantly higher. If adverse selection confers an additional $25 \%$ mortality risk, ${ }^{21}$ this would imply an individual-level mortality reduction from gaining insurance of 38\%, consistent with several prior estimates (Goodman-Bacon, 2013; Hadley, 2003; Wilper et al., 2009) from the admittedly conflicting literature on the topic. The $95 \%$ confidence intervals in Table 6 provide a lower-bound on the individual-level risk reduction of $25 \%$.

To further explore whether these results are solely due to mortality changes in New York, I

\footnotetext{
${ }^{21}$ The extent of adverse selection could actually be much larger than this, given that Medicaid enrollment often occurs at the point-of-care for active medical issues, in doctor's offices, emergency departments, and hospitals.
} 
repeated the regressions using $\Delta$ Coverage in Table 6 with New York excluded from the sample. The resulting coefficient on ExpansionState $* \Delta$ Coverage ranged from -142 to -149 per 100,000 (all $\mathrm{p}<0.05)$. These estimates are roughly half as large as those for the full sample including New York. These findings suggest that the coverage expansions in Maine and Arizona were linked to smaller mortality reductions than in New York, though the non-significant results in the overall Din-D model appear to be due to lack of power compared to effects that are detectable in models focused on county-level coverage changes.

\section{COST-BENEFIT ANALYSIS AND CONCLUSION}

The relationship between coverage gains and mortality changes offers a straightforward way to assess the cost-benefit ratio of Medicaid's impact on population mortality. Of course, many if not most of the benefits of coverage are not due to mortality reductions. Health-related quality of life and financial protection are far more common benefits of coverage. One previous analysis suggested a utility-based gain from financial risk protection in Medicaid equivalent to a value ranging from roughly $\$ 500$ to $\$ 3000$ per person, depending on the extent of risk aversion (Sommers \& Oellerich, 2013), and a recent working paper found substantial improvements in debt related to the ACA's Medicaid expansion equal to a $\$ 600-\$ 1000$ per person reduction in collection balances (Hu, Kaestner, Mazumder, Miller, \& Wong, 2016). Meanwhile, OHIE found that Medicaid increased the proportion of adults reporting "good, very good, or excellent health" by 13 percentage points (Finkelstein et al., 2012) and reduced depression by 9 percentage points (Baicker et al., 2013), as part of a larger welfare gain among beneficiaries equal to $20-40 \%$ of total Medicaid spending (Finkelstein, Hendren, \& Luttmer, 2015). While these financial and non-mortality health benefits are key elements of a comprehensive assessment of Medicaid, here I focus simply on mortality because this allows for a direct comparison to the existing literature on the value of a 
statistical life for various public policy and health interventions.

In the previous section, I estimated that the Medicaid expansion covered 239-316 adults to prevent one death per year. The Oregon Health Insurance Experiment, studying a similar population of low-income adults eligible for a Medicaid expansion, detected a $25 \%$ increase in overall medical spending from gaining Medicaid (Finkelstein et al., 2012). ${ }^{22}$ Thus, each death prevented in my analysis leads to an estimated increase in health care spending of $\$ 186,000$ to $\$ 246,000$, based on the number-needed-to-treat.

However, this does not account for the fact that Medicaid expansion replaces with taxsupported insurance coverage the other $75 \%$ of medical spending that was primarily occurring using private dollars - either out-of-pocket spending or uncompensated care. While some of this pre-expansion care was likely publicly-financed to begin with via public hospitals and clinics, I make the conservative assumption that it was all privately funded - which means that these results provide an upper bound on the cost per life saved. Factoring in the deadweight loss of this crowdout of private medical spending, we are left with the following formula:

$$
\text { Cost per Life Saved }=N N T^{*}[\$ 778 *(1+D W L)+\$ 3156 * D W L]
$$

where $N N T$ is number needed to treat and $D W L$ is the deadweight loss of public financing as an assessment of the distortionary effect of raising taxes to pay for public programs. Typical estimates in the public economics literature for this DWL range from roughly $15 \%$ to $50 \%$; however, it is worth noting that these estimates are primarily driven by labor supply elasticities, which are themselves the subject of considerable imprecision in the literature (Ballard, Shoven, \&

\footnotetext{
${ }^{22}$ LATE results in Table V from Finkelstein et al. (2012) report an estimated $\$ 778$ increase from a baseline mean of \$3156, in 2007 dollars. While New York has the nation's most expensive Medicaid program, this is mostly due to costs for elderly adults and individuals with disabilities. The OHIE estimate for per-person spending among nonelderly adults in Medicaid (\$3934) is quite similar to a contemporary estimate of per capita costs for non-elderly adults in New York's Medicaid program: \$3953 in 2003 dollars, equal to \$4454 in 2007 dollars (www.cbcny.org/sites/default/files/reportsummary_medicaid_04202006.pdf). Replacing the baseline level of spending from OHIE with the latter estimate simply increases the results proportionately, by $13 \%$.
} 
Whalley, 1985; Browning, 1987). ${ }^{23}$ This range, combined with the set of values for NNT estimated above, produces a cost per life saved ranging from $\$ 327,000$ to $\$ 867,000$ (Appendix Table A.4) in 2007 dollars. ${ }^{24}$ These values compare favorably to estimates from the literature on the value of a statistical life (Viscusi, 1992, 1993) used by the government to evaluate public health and environmental policies, which have been pegged at a mean of $\$ 7.6$ million, with a range from $\$ 950,000$ to $\$ 21.4$ million, in 2007 inflation-adjusted dollars (Robinson, 2007).

In conclusion, in this differences-in-differences analysis of state Medicaid expansions to low income adults, I find that expansions led to a $6 \%$ relative decline in mortality over five years of follow-up, compared to a control group of counties with similar pre-expansion mortality trends and demographic features. There was a highly significant decline in healthcare-amenable causes of death, while effects for other causes of death were generally smaller and only marginally significant. Declines in HIV-related deaths accounted for $20 \%$ of the overall mortality effect, and the Medicaid expansions appear to have facilitated the impact of antiretroviral therapy during this period. Mortality declines were closely linked to county-level changes in insurance coverage, with one death prevented annually for every 239 to 316 adults gaining health insurance, which implies a cost per life saved that compares favorably to the standards use to evaluate existing public policy interventions.

\footnotetext{
${ }^{23}$ Note that this DWL does not include the moral hazard of health insurance (i.e. increased utilization due to the reduced cost of care), which in my calculation is already directly captured by the changes in medical spending derived from the OHIE results.

${ }^{24}$ Several back-of-the-envelope cost-benefit analyses have been advanced following the publication of the Massachusetts mortality study (Cannon, 2014; Pollack, 2014). However, these typically have treated the government payment towards subsidized coverage as the "cost of insurance." This is incorrect for two reasons. First, we are interested in the marginal societal cost, and in the absence of subsidized coverage uninsured people do not consumer zero health care - they appear to consume nearly $80 \%$ of what insured people do, according to the OHIE. Second, this approach ignores the deadweight loss of public financing. The first omission is much larger than the second, which means that these previous estimates overstate the cost-per-life compared to the method here.
} 


\section{REFERENCES}

Abadie, A., Diamond, A., \& Hainmueller, J. (2012). Comparative Politics and the Synthetic Control Method. Cambridge, MA: Harvard Kennedy School.

Arellano, A. B. R., \& Wolfe, S. M. (2007). Unsettling scores: a ranking of state Medicaid programs. Washington, DC: Public Citizen.

Artiga, S., \& Mann, C. (2005). Coverage gains under recent Section 1115 waivers: a data update. Washington, D.C.: Kaiser Family Foundation.

Austin, P. C. (2011). Optimal caliper widths for propensity-score matching when estimating differences in means and differences in proportions in observational studies. Pharm Stat, 10(2), 150-161. doi: 10.1002/pst.433

Baicker, K., Taubman, S., Allen, H., Bernstein, M., Gruber, J., Newhouse, J. P., . . Group, O. H. S. (2013). The Oregon Experiment - Effects of Medicaid on Clinical Outcomes. The New England journal of medicine, 368(18), 1713-1722.

Ballard, C. L., Shoven, J. B., \& Whalley, J. (1985). General equilibrium computations of the marginal welfare costs of taxes in the United States. American Economic Review, 75, 128-138.

Bertrand, M., Duflo, E., \& Mullainathan, S. (2004). How Much Should We Trust Differences-inDifferences Estimates? Quarterly Journal of Economics, 119, 249-275.

Black, B., Espin-Sanchez, J. A., French, E., \& Litvak, K. (2013). The Effect of Health Insurance on Near-Elderly Health and Mortality Social Science Research Network.

Brown, G. K., Ten Have, T., Henriques, G. R., Xie, S. X., Hollander, J. E., \& Beck, A. T. (2005). Cognitive therapy for the prevention of suicide attempts: a randomized controlled trial. JAMA : the journal of the American Medical Association, 294(5), 563-570. doi: 10.1001/jama.294.5.563

Browning, E. K. (1987). On the marginal welfare cost of taxation. American Economic Review, $77,11-23$.

Cannon, M. (2014). New Study Suggests RomneyCare Saved Lives, but at a Very High Cost: Forbes.com.

Card, D., Dobkin, C., \& Maestas, N. (2009). Does Medicare Save Lives? Quarterly Journal of Economics, 124(2), 597-636.

Courtemanche, C., Marton, J., Ukert, B., Yelowitz, A., \& Zapata, D. (2016). Impacts of the Affordable Care Act on Health Insurance Coverage in Medicaid Expansion and NonExpansion States NBER Working Paper 22182. Cambridge, MA: National Bureau of Economic Research.

Currie, J., \& Gruber, J. (1996a). Health insurance eligibility, utilization of medical care and child health. Quarterly Journal of Economics, 111(2), 431-466.

Currie, J., \& Gruber, J. (1996b). Saving Babies: The Efficacy and Cost of Recent Expansions of Medicaid Eligibility for Pregnant Women. Journal of Political Economy, 104(6), 12631296.

Decker, S. L. (2013). Two-thirds of primary care physicians accepted new Medicaid patients in 2011-12: a baseline to measure future acceptance rates. Health affairs, 32(7), 1183-1187.

DeLeire, T., Dague, L., Leininger, L., Voskuil, K., \& Friedsam, D. (2013). Wisconsin Experience Indicates that Expanding Public Insurance to Low-Income Childless Adults Has Health Care Impacts. Health affairs, 32(6), 1037-1045. 
DeNavas-Walt, C., Proctor, B., \& Smith, J. (2011). Income, poverty, and health insurance coverage in the United States: 2010. Washington, DC: U.S. Census Bureau.

Doyle, J. J. (2005). Health insurance, treatment and outcomes: using auto accidents as health shocks. Review of Economics and Statistics, 87(2), 256-270.

Duggan, M. G., \& Evans, W. N. (2008). Estimating the Impact of Medical Innovation: A Case Study of HIV Antiretroviral Treatments. Forum for Health Economics \& Policy, 11(2), Article 1.

Epstein, A. M., \& Newhouse, J. (1998). The impact in Medicaid expansion for pregnant women on early prenatal care, use of cesarean section and maternal and infant health outcomes in South Carolina and California. Health Care Finance Review, 19(4), 85-99.

Fergusson, D., Doucette, S., Glass, K. C., Shapiro, S., Healy, D., Hebert, P., \& Hutton, B. (2005). Association between suicide attempts and selective serotonin reuptake inhibitors: systematic review of randomised controlled trials. $B M J, 330(7488), 396$. doi: 10.1136/bmj.330.7488.396

Finkelstein, A., Hendren, N., \& Luttmer, E. F. P. (2015). The Value of Medicaid: Interpreting Results from the Oregon Health Insurance Experiment NBER Working Paper 21308. Cambridge, MA: National Bureau of Economic Research.

Finkelstein, A., \& McKnight, R. (2008). What did Medicare do? The initial impact of Medicare on mortality and out of pocket medical spending. Journal of Public Economics, 92, 16441668.

Finkelstein, A., Taubman, S., Wright, B. J., Bernstein, M., Gruber, J., Newhouse, J. P., . . . Group, O. H. S. (2012). The Oregon Health Insurance Experiment: Evidence from the First Year. Quarterly Journal of Economics, 127(3), 1057-1106.

Frakt, A. (2013). Power calculations for the Oregon Medicaid study. Incidental Economist.

Galea, S., Tracy, M., Hoggatt, K. J., Dimaggio, C., \& Karpati, A. (2011). Estimated deaths attributable to social factors in the United States. American journal of public health, 101(8), 1456-1465.

Goldman, D., Bhattacharya, J., McCaffrey, D., Duan, N., Leibowitz, A., Joyce, G., \& Morton, S. (2001). The Effect of Insurance on Mortality in an HIV+ Population in Care. Journal of the American Statistical Association, 96(455), 883-894.

Goodman-Bacon, A. (2013). Public Insurance and Mortality: Evidence from Medicaid Implementation. Ann Arbor, MI: University of Michigan Working Paper.

Gordon, S., \& Sommers, B. D. (2015). Recessions, Poverty, and Mortality in the United States: 1993-2012. American Journal of Health Economics, In Press.

Greene, W. (2005). Functional form and heterogeneity in models for count data. Foundations and Trends in Econometrics, 1(2), 113-218.

Hadley, J. (2003). Sicker and poorer: the consequences of being uninsured. Medical Care Research and Review, 60(2), 3S-75S.

Hawton, K., Townsend, E., Arensman, E., Gunnell, D., Hazell, P., House, A., \& van Heeringen, K. (2000). Psychosocial versus pharmacological treatments for deliberate self harm. Cochrane Database Syst Rev(2), CD001764. doi: 10.1002/14651858.CD001764

Howell, E. M. (2001). The impact of the Medicaid expansions for pregnant women: a synthesis of the evidence. Medical care research and review : MCRR, 58(1), 3-30.

Hu, L., Kaestner, R., Mazumder, B., Miller, S., \& Wong, A. (2016). The Effect of the Patient Protection and Affordable Care Act Medicaid Expansions on Financial Well-Being NBER Working Paper 22170. Cambridge, MA: National Bureau of Economic Research. 
Kaestner, R. (2012). Mortality and access to care after Medicaid expansions. The New England journal of medicine, 367(25), 2453-2454; author reply 2454.

Kaiser. (2013). The Ryan White Program. Washington, DC: Kaiser Family Foundation.

Kenney, G. M., Lynch, V., Haley, J., \& Huntress, M. (2012). Variation in Medicaid eligibility and participation among adults: implications for the Affordable Care Act. Inquiry : $a$ journal of medical care organization, provision and financing, 49, 231-253.

Kronick, R. (2009). Health insurance coverage and mortality revisited. Health services research, 44(4), 1211-1231.

Long, S. K., Coughlin, T., \& King, J. (2005). How well does Medicaid work in improving access to care? Health services research, 40(1), 39-58.

McCall, N. (1997). Lessons from Arizona's Medicaid managed care program. Health affairs, 16(4), 194-199.

Miller, S. (2012). The effect of insurance on emergency room visits: An analysis of the 2006 Massachusetts health reform. J Pub Econ, 96(11-12), 893-908.

Nolte, E., \& McKee, C. M. (2008). Measuring the health of nations: updating an earlier analysis. Health affairs, 27(1), 58-71.

Nolte, E., \& McKee, M. (2003). Measuring the health of nations: analysis of mortality amenable to health care. $B M J, 327(7424), 1129$.

Organization, W. H. (2000). The World Health Report 2000.

Palella, F. J., Jr., Baker, R. K., Moorman, A. C., Chmiel, J. S., Wood, K. C., Brooks, J. T., \& Holmberg, S. D. (2006). Mortality in the highly active antiretroviral therapy era: changing causes of death and disease in the HIV outpatient study. Journal of acquired immune deficiency syndromes, 43(1), 27-34. doi: 10.1097/01.qai.0000233310.90484.16

Pauly, M. V., \& Pagan, J. A. (2007). Spillovers and vulnerability: the case of community uninsurance. Health affairs, 26(5), 1304-1314.

Pollack, H. (2014). Could Obamacare save 24,000 lives a year? : Healthinsurance.org.

Robinson, L. A. (2007). How US Government Agencies Value Mortality Risk Reductions. Review of Environmental Economics and Policy, 1(2), 283-299.

Roy, A. (2013). How Medicaid Fails the Poor. Jackson, TN: Encounter Books.

Ruhm, C. J. (2000). Are Recessions Good for Your Health? Quarterly Journal of Economics, $115(2), 617-650$.

Ruhm, C. J. (2005). Commentary: mortality increases during economic upturns. International journal of epidemiology, 34(6), 1206-1211.

Sommers, B. D., Long, S. K., \& Baicker, K. (2014). Changes in Mortality After Massachusetts Health Care Reform: A Quasi-experimental Study. Annals of internal medicine, 160(9), 585-593. doi: 10.7326/M13-2275

Sommers, B. D., \& Oellerich, D. (2013). The poverty-reducing effect of Medicaid. Journal of health economics, 32(5), 816-832.

Viscusi, W. K. (1992). Fatal Trade-offs: Public and Private Responsibilities for Risk. New York: Oxford University Press.

Viscusi, W. K. (1993). The value of risks to life and health. Journal of Economic Literature, 31, 1912-1946.

Weil, A. (2003). There's something about Medicaid. Health affairs, 22(1), 13-30.

Wilper, A. P., Woolhandler, S., Lasser, K. E., McCormick, D., Bor, D. H., \& Himmelstein, D. U. (2009). Health insurance and mortality in US adults. American journal of public health, 99(12), 2289-2295. 


\section{TABLE 1: Baseline Features (1997-2000) of Medicaid Expansion States, Alternative Control Groups, and All Non-Expansion States}

\begin{tabular}{|c|c|c|c|c|c|c|}
\hline Variable & Expansion States & PS Control & Neighboring Control & Rest of U.S. & $\begin{array}{l}\text { Standardized } \\
\text { Difference, } \\
\text { Expansion vs. } \\
\text { PS Control }\end{array}$ & $\begin{array}{c}\text { Standardized } \\
\text { Difference, } \\
\text { Expansion vs. } \\
\text { Neighboring } \\
\text { Control }\end{array}$ \\
\hline Age $20-24$ & $11.0 \%$ & $10.6 \%$ & $10.5 \%$ & $11.3 \%$ & 0.18 & 0.23 \\
\hline Age $25-34$ & $25.3 \%$ & $25.3 \%$ & $23.3 \%$ & $24.9 \%$ & 0.01 & 0.68 \\
\hline Age $35-44$ & $27.1 \%$ & $27.5 \%$ & $27.8 \%$ & $27.5 \%$ & -0.22 & -0.41 \\
\hline Age $45-54$ & $21.9 \%$ & $22.0 \%$ & $23.0 \%$ & $22.0 \%$ & -0.06 & -0.60 \\
\hline Age $55-64$ & $14.7 \%$ & $14.6 \%$ & $15.4 \%$ & $14.2 \%$ & 0.02 & -0.43 \\
\hline Male & $49.0 \%$ & $49.2 \%$ & $49.5 \%$ & $49.7 \%$ & -0.20 & -0.30 \\
\hline White & $79.2 \%$ & $81.2 \%$ & $88.3 \%$ & $82.7 \%$ & -0.14 & -0.57 \\
\hline Black & $14.0 \%$ & $10.7 \%$ & $8.1 \%$ & $12.2 \%$ & 0.26 & 0.46 \\
\hline Other Race & $6.9 \%$ & $8.0 \%$ & $3.6 \%$ & $5.1 \%$ & -0.12 & 0.49 \\
\hline Latino Ethnicity & $15.9 \%$ & $15.7 \%$ & $8.3 \%$ & $11.1 \%$ & 0.01 & 0.56 \\
\hline Poverty Rate & $14.2 \%$ & $12.9 \%$ & $10.8 \%$ & $12.0 \%$ & 0.20 & 0.58 \\
\hline Median Household Income & $\$ 53,866$ & $\$ 57,880$ & $\$ 53,629$ & $\$ 55,150$ & -0.24 & 0.02 \\
\hline Unemployment Rate & $5.3 \%$ & $4.8 \%$ & $4.6 \%$ & $4.4 \%$ & 0.20 & 0.29 \\
\hline Mortality (per 100,000 ) & 318 & 297 & 343 & 330 & 0.28 & -0.35 \\
\hline Number of counties & 93 & 907 & 127 & 3047 & 1000 & 1000 \\
\hline Number of states & 3 & 47 & 4 & 48 & 50 & 50 \\
\hline
\end{tabular}

\section{Notes:}

Medicaid expansion states were New York, Arizona, and Maine. PS control is the propensity-score defined control group. Neighboring control is the original four-state control group (Pennsylvania, Nevada, New Mexico, and New Hampshire) used in Sommers, Baicker, and Epstein (2012), which were demographically similar states neighboring the expansion states. Sample contains adults ages 20-64. "Rest of U.S." includes 47 states and the District of Columbia. 
TABLE 2: Tests of Pre-Expansion Trends and Placebo Tests for All-Cause Mortality, 1997-2000

\begin{tabular}{lcc}
\hline Specification & Linear Model & Negative Binomial GLM \\
\hline Linear Trend (Equation 2): & 0.69 & -.0064 \\
Expansion State*Time Trend & $(1.18)$ & $(.0063)$ \\
Placebo Test (Equation 3): & 1.80 & -.0096 \\
Expansion State $*$ Year2000 & $(2.21)$ & $(.0145)$ \\
\hline
\end{tabular}

\section{Notes:}

$\mathrm{N}=106,274$ annual county age-race-sex cells.

All coefficients non-significant at $\mathrm{p}>0.10$. Linear model reports changes in deaths per 100,000. Negative binomial generalized linear model (GLM) reports relative change in mortality. Sample contains adults ages 20-64. 
TABLE 3: Effect of State Medicaid Expansions on All-Cause Mortality

\begin{tabular}{lcc}
\hline Model and Variable & Linear Model & Negative Binomial GLM \\
\hline Expansion State * Post-Expansion & $-19.1^{* * *}$ & $-.060^{* * *}$ \\
& $(6.3)$ & $(.023)$ \\
Age 25-34 & $12.2^{* * *}$ & $.085^{* * *}$ \\
& $(2.5)$ & $.027)$ \\
Age 35-44 & $98.6^{* * *}$ & $.79^{* * *}$ \\
& $(5.7)$ & $(.05)$ \\
Age 45-54 & $311.3^{* * *}$ & $1.60^{* * *}$ \\
& $(9.9)$ & $(.05)$ \\
Age 55-64 & $778.6^{* * *}$ & $2.42^{* * *}$ \\
& $(17.7)$ & $(.06)$ \\
Male & $172.6^{* * *}$ & $.68^{* * *}$ \\
& $(7.0)$ & $(.01)$ \\
White & $80.8^{* * *}$ & $.53^{* * *}$ \\
& $(18.8)$ & $(.10)$ \\
Black & $268.9^{* * *}$ & $1.10^{* * *}$ \\
& $(22.5)$ & $(.10)$ \\
\% Latino & 0.38 & $-.006^{* * *}$ \\
& $(0.92)$ & $.002)$ \\
Poverty Rate & $1.35^{* * *}$ & $.014^{* * *}$ \\
Median Household Income & $(0.41)$ & $(.004)$ \\
& $-0.001^{* * *}$ & $-.000006^{* * *}$ \\
Unemployment Rate & $(0.0004)$ & $(.000002)$ \\
& -1.25 & .009 \\
\end{tabular}

Notes:

$* \mathrm{p} \leq 0.10, * * \mathrm{p} \leq 0.05, * * * \mathrm{p} \leq 0.01$

$\mathrm{N}=313,161$ annual county age-race-sex cells.

Linear model reports changes in deaths per 100,000. Negative binomial generalized linear model (GLM) reports relative change in mortality. Robust standard errors, clustered at the state-level $(\mathrm{n}=50)$, are in parentheses. All models include year fixed effects. Linear model also includes county fixed effects, and GLM includes state fixed effects. See Equation 4 in text for full details. Sample contains adults ages 20-64. 
TABLE 4: Effect of State Medicaid Expansions on Mortality, By Cause of Death

\begin{tabular}{lccc}
\hline Cause of Death & Pre-Expansion Mean & Linear Model & Negative Binomial GLM \\
\hline All-Cause Mortality & 318 & $-19.1^{* * *}$ & $-.060^{* * *}$ \\
& & $(6.3)$ & $(.023)$ \\
Healthcare Amenable Mortality & 227 & $-12.0^{* * *}$ & $-.067^{* * *}$ \\
& & $(2.9)$ & $(.014)$ \\
Non-Amenable Mortality§ & 91 & $-7.0^{*}$ & $-.052^{*}$ \\
& & $(3.8)$ & $(.028)$ \\
Non-HIV Mortality & 301 & $-15.3^{* * *}$ & $-0.042^{* *}$ \\
& & $(5.5)$ & $(.019)$ \\
HIV-Related Mortality & 17 & $-3.8^{* * *}$ & $-0.136^{* * *}$ \\
(standard control group) & & $(0.8)$ & $(.032)$ \\
HIV-Related Mortality & 17 & $-2.6^{* *}$ & $-0.154^{* * *}$ \\
(HIV-specific control group) $\dagger$ & & $(1.0)$ & $(.057)$ \\
\end{tabular}

\section{Notes:}

$* \mathrm{p} \leq 0.10, * * \mathrm{p} \leq 0.05, * * * \mathrm{p} \leq 0.01$

$\mathrm{N}=313,161$ annual county age-race-sex cells.

Linear model reports changes in deaths per 100,000. Negative binomial generalized linear model (GLM) reports relative change in mortality. Robust standard errors, clustered at the state-level $(\mathrm{n}=50)$, are in parentheses. All models include year fixed effects. Linear model also includes county fixed effects, and GLM includes state fixed effects. See Equation 4 in text for full details. Sample contains adults ages 20-64.

$\dagger$ "HIV-specific control group" refers to an alternative sample in which the control counties were matched to the expansion counties based on demographic features and pre-expansion HIV-specific mortality rates, rather than allcause mortality rate (the "standard control group").

$\S$ "Non-Amenable" causes of death are those not included in the category "Healthcare Amenable." However, this does not mean they cannot be impacted by health insurance, only that these death rates are likely to be less responsive to insurance coverage than other causes. 


\section{TABLE 5: DDD Estimates of State Medicaid Expansion Effect on Mortality for Non-EIderly Adults}

\begin{tabular}{|c|c|c|c|}
\hline Variable & $\begin{array}{l}\text { All-Cause } \\
\text { Mortality }\end{array}$ & $\begin{array}{l}\text { Health-Care Amenable } \\
\text { Mortality }\end{array}$ & $\begin{array}{c}\text { Non-Amenable } \\
\text { Mortality } \S\end{array}$ \\
\hline ExpansionState $*$ Post-Expansion $*$ Non- & $-.048 *$ & $-.062 * * *$ & -.048 \\
\hline Elderly & $(.027)$ & $(.017)$ & $(.031)$ \\
\hline ExpansionState * Post-Expansion & $\begin{array}{l}-.015^{*} \\
(.008)\end{array}$ & $\begin{array}{l}-.009 \\
(.008)\end{array}$ & $\begin{array}{c}-.009 \\
(.022)\end{array}$ \\
\hline Non-Elderly * ExpansionState & $\begin{array}{l}.028 \\
(.073)\end{array}$ & $\begin{array}{l}.050 \\
(.045)\end{array}$ & $\begin{array}{l}.158^{*} \\
(.087)\end{array}$ \\
\hline Post-Expansion * Non-Elderly & $\begin{array}{c}.110^{* * *} \\
(.009)\end{array}$ & $\begin{array}{l}.030^{* * *} \\
(.006)\end{array}$ & $\begin{array}{c}.086^{* * *} \\
(.019)\end{array}$ \\
\hline Age 25-34 & $\begin{array}{l}.080 * * * \\
(.028)\end{array}$ & $\begin{array}{l}.74 * * * \\
(.03)\end{array}$ & $\begin{array}{c}-.12 * * * \\
(.02)\end{array}$ \\
\hline Age $35-44$ & $\begin{array}{l}.78 * * * \\
(.05)\end{array}$ & $\begin{array}{l}1.94 * * * \\
(.04)\end{array}$ & $\begin{array}{l}.22 * * * \\
(.03)\end{array}$ \\
\hline Age $45-54$ & $\begin{array}{c}1.59 * * * \\
(.05)\end{array}$ & $\begin{array}{c}3.05^{* * * *} \\
(.03)\end{array}$ & $\begin{array}{l}.59 * * * \\
(.03)\end{array}$ \\
\hline Age 55-64 & $\begin{array}{c}2.41 * * * \\
(.06)\end{array}$ & $\begin{array}{c}4.03^{* * *} \\
(.03)\end{array}$ & $\begin{array}{l}.91 * * * \\
(.04)\end{array}$ \\
\hline Age $65-74$ & $\begin{array}{c}3.38 * * * \\
(.07)\end{array}$ & $\begin{array}{c}4.99 * * * \\
(.05)\end{array}$ & $\begin{array}{c}1.75^{* * *} \\
(.09)\end{array}$ \\
\hline Age $75-84$ & $\begin{array}{c}4.35 * * * \\
(.07)\end{array}$ & $\begin{array}{l}5.91 * * * \\
(.05)\end{array}$ & $\begin{array}{l}2.92^{* * * *} \\
(.08)\end{array}$ \\
\hline Age 85 and older & $\begin{array}{l}5.51 * * * \\
(.06)\end{array}$ & $\begin{array}{c}6.97^{* * *} \\
(.04)\end{array}$ & $\begin{array}{c}4.35^{* * *} \\
(.09)\end{array}$ \\
\hline Male & $\begin{array}{l}.62 * * * \\
(.01)\end{array}$ & $\begin{array}{c}.40 * * * \\
(.01)\end{array}$ & $\begin{array}{l}.80 * * * \\
(.02)\end{array}$ \\
\hline White & $\begin{array}{l}.52 * * * \\
(.10)\end{array}$ & $\begin{array}{c}.43 * * * \\
(.08)\end{array}$ & $\begin{array}{l}.69 * * * \\
(.13)\end{array}$ \\
\hline Black & $\begin{array}{c}1.06 * * * \\
(.09)\end{array}$ & $\begin{array}{c}1.10^{* * * *} \\
(.06)\end{array}$ & $\begin{array}{c}1.07^{* * *} \\
(.14)\end{array}$ \\
\hline$\%$ Latino & $\begin{array}{c}-.005 * * * \\
(.001)\end{array}$ & $\begin{array}{l}-.002 * \\
(.001)\end{array}$ & $\begin{array}{c}-.009 * * * \\
(.002)\end{array}$ \\
\hline Poverty Rate & $\begin{array}{l}.013 * * * \\
(.004)\end{array}$ & $\begin{array}{l}.013 * * * \\
(.002)\end{array}$ & $\begin{array}{l}.011 \\
(.007)\end{array}$ \\
\hline Median Household Income & $\begin{array}{l}-.000005^{* * * *} \\
(.000001)\end{array}$ & $\begin{array}{c}-.000005^{* * *} \\
(.000001)\end{array}$ & $\begin{array}{c}-.000006^{* * *} \\
(.000001)\end{array}$ \\
\hline Unemployment Rate & $\begin{array}{c}.007 \\
(.006)\end{array}$ & $\begin{array}{l}-.001 \\
(.004)\end{array}$ & $\begin{array}{l}.013 \\
(.009)\end{array}$ \\
\hline
\end{tabular}

\section{Notes:}

$* \mathrm{p} \leq 0.10, * * \mathrm{p} \leq 0.05, * * * \mathrm{p} \leq 0.01$

$\mathrm{N}=456,660$ annual county age-race-sex cells.

Coefficients report relative change in mortality. Robust standard errors, clustered at the state-level $(\mathrm{n}=50)$, are in parentheses. All estimates are from a negative binomial generalized linear model, which includes year fixed effects and state fixed effects. See Equation 5 in text for full details. Sample contains adults ages 20 and older.

$\S$ "Non-Amenable" causes of death are those not included in the category "Healthcare Amenable." However, this does not mean they cannot be impacted by health insurance, only that these death rates are likely to be less responsive to insurance coverage than other causes. 


\section{TABLE 6: Mortality and County Level Coverage Changes Due to Medicaid Expansions}

\begin{tabular}{|c|c|c|c|c|c|c|}
\hline Model and Variable & (1) & (2) & (3) & (4) & (5) & (6) \\
\hline Years Included & All & All & $\begin{array}{c}2000 \\
2005-07\end{array}$ & 2000,2007 & $\begin{array}{c}2000 \\
2005-07\end{array}$ & 2000,2007 \\
\hline $\begin{array}{l}\text { High Uninsured Counties: } \\
\text { ExpansionState *Post }\end{array}$ & $\begin{array}{l}-29.4^{* *} \\
(12.1)\end{array}$ & - & - & - & - & - \\
\hline $\begin{array}{l}\text { Low Uninsured Counties: } \\
\text { ExpansionState*Post }\end{array}$ & $\begin{array}{c}-7.7 * * * \\
(2.7)\end{array}$ & - & - & - & - & - \\
\hline ExpansionState $*$ Post $*$ Uninsured_2000 & - & $\begin{array}{c}-99.4 * * \\
(46.6)\end{array}$ & - & - & - & - \\
\hline ExpansionState $* \Delta$ Coverage & - & - & $\begin{array}{l}-328.1 * * * \\
(56.8)\end{array}$ & $\begin{array}{l}-419.2 * * * \\
(76.5)\end{array}$ & $\begin{array}{c}-316.0 * * * \\
(48.2)\end{array}$ & $\begin{array}{c}-390.6 * * * \\
(74.7)\end{array}$ \\
\hline$\Delta$ Coverage & - & - & $\begin{array}{c}100.0^{* *} \\
(37.6)\end{array}$ & $\begin{array}{l}94.6 * * \\
(45.1)\end{array}$ & $\begin{array}{c}116.4 * * * \\
(41.4)\end{array}$ & $\begin{array}{l}99.7^{*} \\
(54.3)\end{array}$ \\
\hline ExpansionState*Post & - & - & - & - & $\begin{array}{c}-23.7 * * * \\
(6.7)\end{array}$ & $\begin{array}{c}-23.8 * * * \\
(-4.9)\end{array}$ \\
\hline
\end{tabular}

Notes:

$* \mathrm{p} \leq 0.10, * * \mathrm{p} \leq 0.05, * * * \mathrm{p} \leq 0.01$

Model 1 is the baseline linear model with the sample stratified into high-uninsured and low-uninsured counties based on 2000 SAHIE estimates.

Model 2 is described by Equation 6 in the text and measures the interaction term between ExpansionStatePost and the pre-expansion uninsured rate (based on 2000 SAHIE estimates).

Model 3 is described by Equation 7 in the text and includes all 3 years with SAHIE estimates (2000, 2005-2007). Model 4 is analogous to Model 2, but uses only 2000 and 2007 data.

Models 5-6 repeat Models 3-4, respectively, with the addition of the term ExpansionState*Post. $\Delta$ Coverage is the net change in the county-level uninsured rate for non-elderly adults, from pre-expansion to post-expansion.

Coefficients report changes in mortality per 100,000. Robust standard errors, clustered at the state-level $(\mathrm{n}=50)$, are in parentheses. All models include year fixed effects and county fixed effects. Sample contains adults ages 20-64. 
FIGURE 1: Mortality Rates (per 100,000) for Adults 20-64 in Medicaid Expansion and Control States, 1997-2007

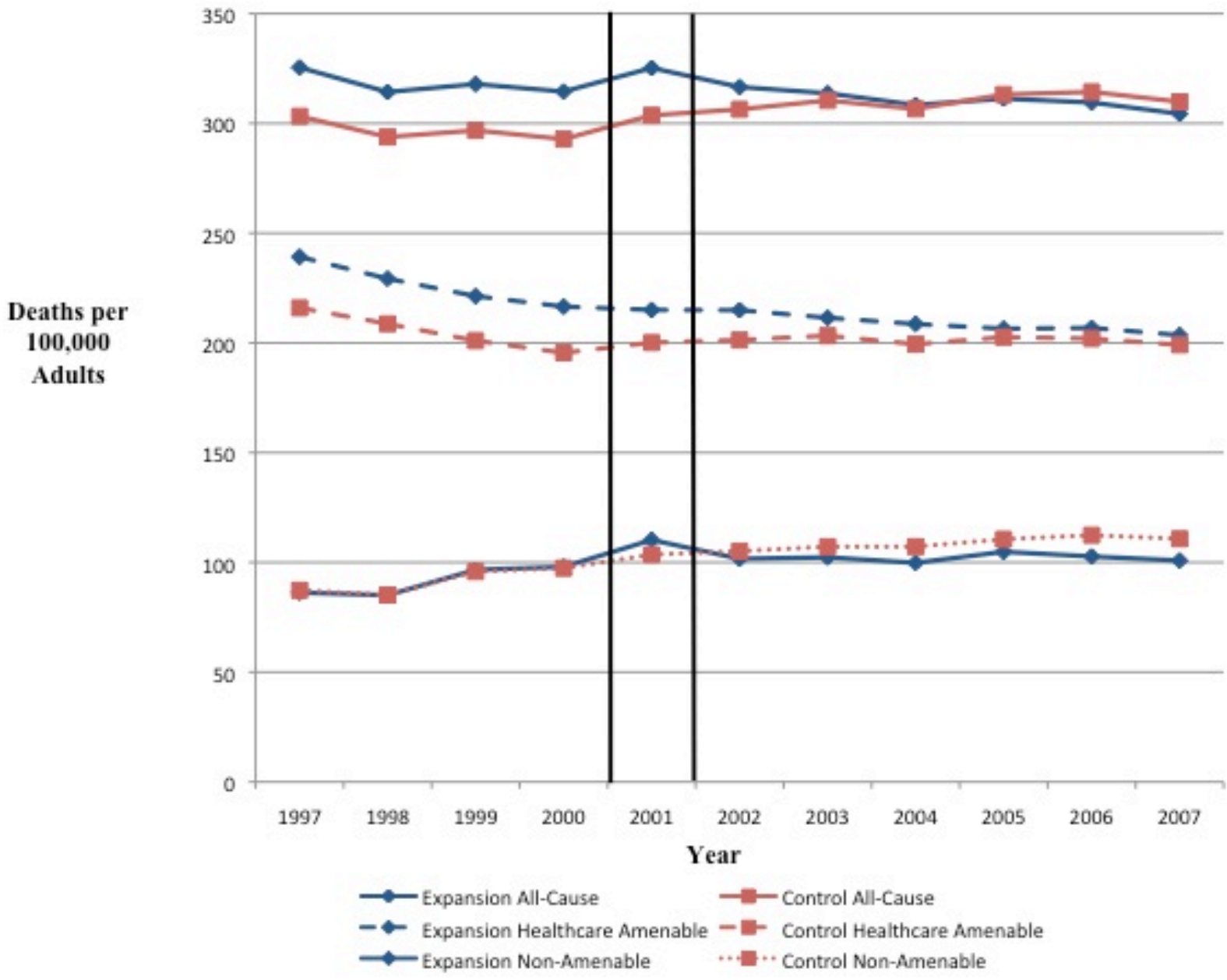

Notes:

Solid black lines indicate the beginning of the Medicaid expansions in New York and Arizona (2001) and Maine (2002).

"Non-Amenable" causes of death are those not included in the category "Healthcare Amenable." However, this does not mean they cannot be impacted by health insurance, only that these death rates are likely to be less responsive to insurance coverage than other causes. 
FIGURE 2: HIV Mortality Rates (per 100,000) for Adults 20-64 in Medicaid Expansion and Control States, 1997-2007

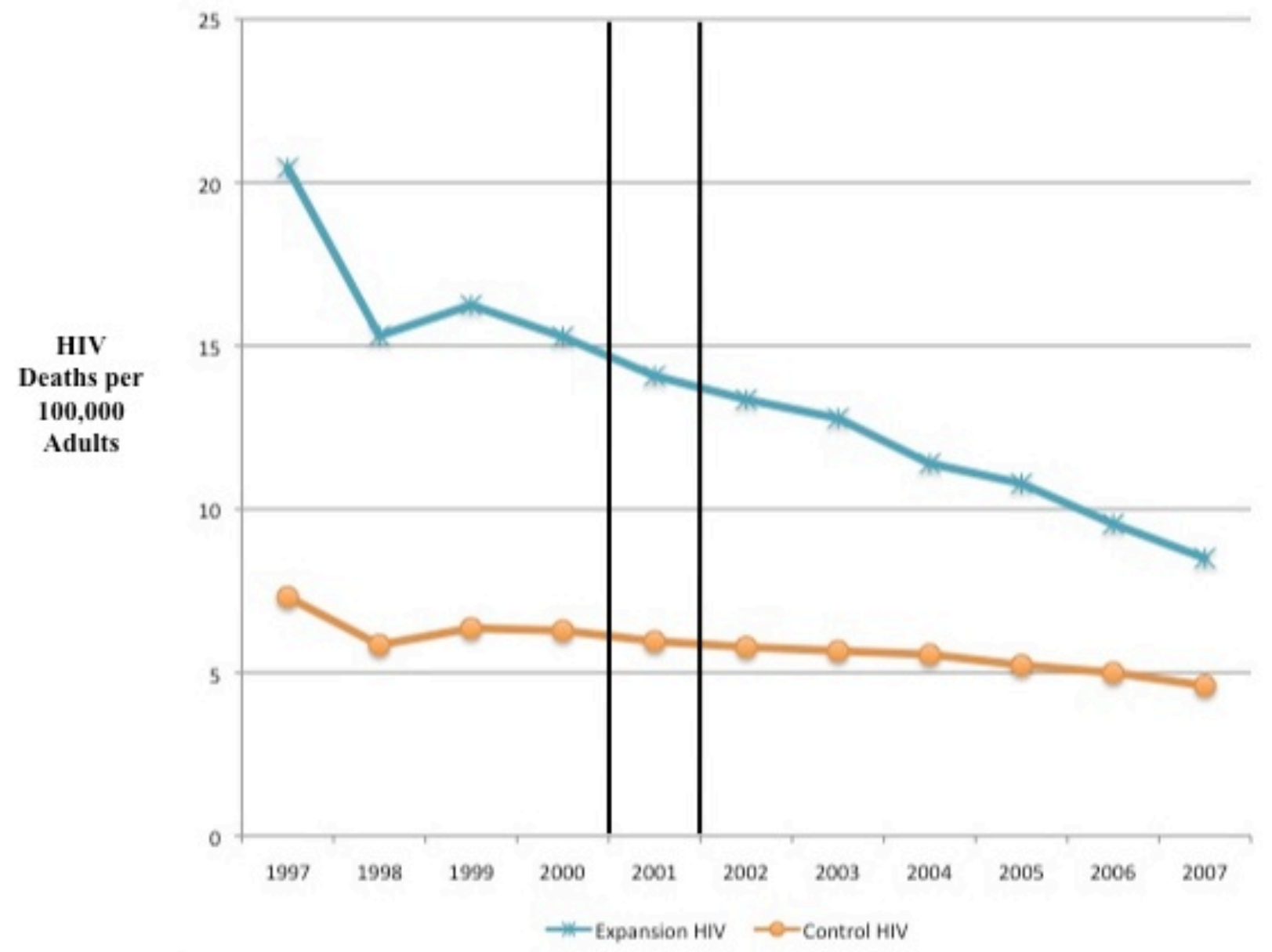

Notes:

Solid black lines indicate the beginning of the Medicaid expansions in New York and Arizona (2001) and Maine (2002). 


\section{APPENDIX TABLE A.1: \\ Propensity Score Regression Results \\ for Probability of Being a Medicaid Expansion County}

\begin{tabular}{lccc}
\hline Variable & Logit Coefficient & Standard Error & p-value \\
\hline \% Age20_24 & -45.65 & 9.40 & $<0.001$ \\
\% Age25_34 & -23.29 & 11.66 & 0.046 \\
\% Age35_44 & -40.12 & 12.02 & 0.001 \\
\% Age45_54 & -43.53 & 17.46 & 0.01 \\
\% Age55_64 (omitted reference group) & $\mathrm{N} / \mathrm{A}$ & $\mathrm{N} / \mathrm{A}$ & $\mathrm{N} / \mathrm{A}$ \\
\% Male & -30.85 & 14.44 & 0.03 \\
\% White & -0.44 & 2.49 & 0.86 \\
\% Black & 1.20 & 1.96 & 0.54 \\
\% Latino & -4.55 & 2.20 & 0.04 \\
\% Other Race (omitted reference group) & $\mathrm{N} / \mathrm{A}$ & $\mathrm{N} / \mathrm{A}$ & $\mathrm{N} / \mathrm{A}$ \\
Poverty Rate & 26.59 & 6.73 & $<0.001$ \\
Median Household Income & 0.00002 & 0.00003 & 0.52 \\
Unemployment Rate & 1.85 & 10.08 & 0.86 \\
All-Cause Death Rate 1997 & -0.002 & 0.002 & 0.36 \\
All-Cause Death Rate 1998 & -0.005 & 0.002 & 0.04 \\
All-Cause Death Rate 1999 & -0.001 & 0.003 & 0.73 \\
All-Cause Death Rate 2000 & -0.010 & 0.003 & $<0.001$ \\
\hline
\end{tabular}

Notes:

$* \mathrm{p} \leq 0.10, * * \mathrm{p} \leq 0.05, * * * \mathrm{p} \leq 0.01$

Model is a county-level analysis, weighted by population size, where the outcome was a binary indicator for

Medicaid expansion status. See Equation 1 in the text. All-Cause Death Rate is expressed as deaths per 100,000. 


\section{APPENDIX TABLE A.2: \\ Additional Robustness Checks for DD Estimates of All-Cause Mortality}

\begin{tabular}{lcc}
\hline Model and Variable & Linear Model & Negative Binomial GLM \\
\hline Pooled Pre- vs. Post-Expansion Data: & $-19.11^{* *}$ & $-.065^{* * *}$ \\
Expansion State * Post-Expansion & $(2.5)$ & $(.018)$ \\
State-Level Data: & $-20.5^{* * *}$ & $-.059^{* * *}$ \\
Expansion State * Post-Expansion & $(4.1)$ & $(.011)$ \\
Including 2001 as Pre-Expansion: & $-18.9^{* * *}$ & $-.069^{* *}$ \\
Expansion State * Post-Expansion & $(6.6)$ & $(.028)$ \\
Interrupted Times Series: & $-4.3^{* * *}$ & $-.014^{* *}$ \\
Expansion State * Years Post & $(1.3)$ & $(.006)$ \\
Adding 2008-2010 Data: & $-22.5^{* * *}$ & $-.062^{* * *}$ \\
Expansion State * Post-Expansion & $(6.3)$ & $(.021)$ \\
& & \\
2:1 Nearest Neighbor Propensity Match $\dagger$ & $-13.5^{* *}$ & $-.060^{* * *}$ \\
Expansion State * Post-Expansion & & $-.062^{* * *}$ \\
3:1 Nearest Neighbor Propensity Match $\dagger$ & $-14.7^{* *}$ & $-.044^{* *}$ \\
Expansion State * Post-Expansion & & \\
5:1 Nearest Neighbor Propensity Match $\dagger$ & $-14.6^{* * *}$ & \\
Expansion State * Post-Expansion & & $-.056^{* * *}$ \\
& & $(.022)$ \\
Non-HIV Matched Control Group $\S$ & $-17.2^{* *}$ & $-.040^{* *}$ \\
Expansion State * Post-Expansion (All-Cause Mortality) & $(6.6)$ & $(.017)$ \\
Non-HIV Matched Control Group $\S$ & $-13.7^{* *}$ & \\
Expansion State * Post-Expansion (Non-HIV Mortality) & $(5.8)$ & \\
& & \\
\hline
\end{tabular}

Notes:

$* \mathrm{p} \leq 0.10, * * \mathrm{p} \leq 0.05, * * * \mathrm{p} \leq 0.01$

Linear model reports changes in deaths per 100,000. Negative binomial generalized linear model (GLM) reports relative change in mortality. Robust standard errors, clustered at the state-level $(\mathrm{n}=50)$, are in parentheses. All models include year fixed effects. Linear model also includes county fixed effects (except in the state-level model), and GLM includes state fixed effects. Sample contains adults ages 20-64.

$\S$ These models use a control group selected using a propensity score approach as defined in Equation 1, with the replacement of Annual All-Cause Mortality (1997-2000) in the propensity score regression with Annual Non-HIV Mortality (1997-2000).

$\dagger$ These models use $n: 1$ propensity score matching without replacement, with a caliper size equal to 0.2 times the standard deviation of the logit(propensity score), based on Austin (2011). 


\section{APPENDIX TABLE A.3: \\ Effect of State Medicaid Expansions on Mortality, By Cause of Death, Excluding New York}

\begin{tabular}{lccc}
\hline Cause of Death & Pre-Expansion Mean & Linear Model & Negative Binomial GLM \\
\hline All-Cause Mortality & 325 & -0.7 & .009 \\
& & $(2.7)$ & $(.009)$ \\
Healthcare Amenable Mortality & 207 & -2.1 & $-.027^{* *}$ \\
& & $(1.5)$ & $(.012)$ \\
Non-Amenable Mortality§ & 118 & 1.3 & -.003 \\
& & $(1.9)$ & $(.016)$ \\
HIV-Related Mortality & 5 & -0.1 & 0.009 \\
& & $(0.2)$ & $(.008)$ \\
Non-HIV Mortality & 321 & -0.7 & 0.045 \\
& & $(2.6)$ & $(.038)$ \\
\hline
\end{tabular}

Notes:

$* \mathrm{p} \leq 0.10, * * \mathrm{p} \leq 0.05, * * * \mathrm{p} \leq 0.01$

$\mathrm{N}=423,531$ annual county age-race-sex cells. Note that the total county count is higher here than in Tables $2-4$, even though the population represented is smaller, because New York counties (and counties similar to it in the propensity score match) are more populous on average than those in other states.

Linear model reports changes in deaths per 100,000. Negative binomial generalized linear model (GLM) reports relative change in mortality. Robust standard errors, clustered at the state-level $(\mathrm{n}=50)$, are in parentheses. All models include year fixed effects. Linear model also includes county fixed effects, and GLM includes state fixed effects. See Equation 4 in text for full details. Sample contains adults ages 20-64. Numbers may not sum due to rounding.

$\S$ "Non-Amenable" causes of death are those not included in the category "Healthcare Amenable." However, this does not mean they cannot be impacted by health insurance, only that these death rates are likely to be less responsive to insurance coverage than other causes. 


\section{APPENDIX TABLE A.4: Cost Per Life Saved Under Medicaid Expansions (2007 dollars)}

\begin{tabular}{ccccc}
\hline & & \multicolumn{3}{c}{ Deadweight Loss of Public Financing } \\
& & \multicolumn{3}{c}{ (DWL) } \\
\cline { 2 - 5 } & & $15 \%$ & $30 \%$ & $50 \%$ \\
\cline { 2 - 5 } \multirow{2}{*}{$\begin{array}{c}\text { Number Needed to Treat } \\
\text { (NNT) }\end{array}$} & 239 & $\$ 327,000$ & $\$ 468,000$ & $\$ 656,000$ \\
& 316 & $\$ 432,000$ & $\$ 619,000$ & $\$ 867,000$ \\
\hline
\end{tabular}

\section{Notes:}

Values come from the following formula: Total Cost per Life Saved $=N N T *[\$ 778 *(1+D W L)+\$ 3156 * D W L]$ Figures for additional health care spending per person with Medicaid (\$778) and baseline spending for uninsured low income adult gaining Medicaid (\$3156) are both from Finkelstein et al. (2012).

All terms are in 2007 dollars and rounded to the nearest thousand. 
APPENDIX FIGURE A.1: Mortality Rates (per 100,000) for Adults 65 and Older in Medicaid Expansion and Control States, 1997-2007

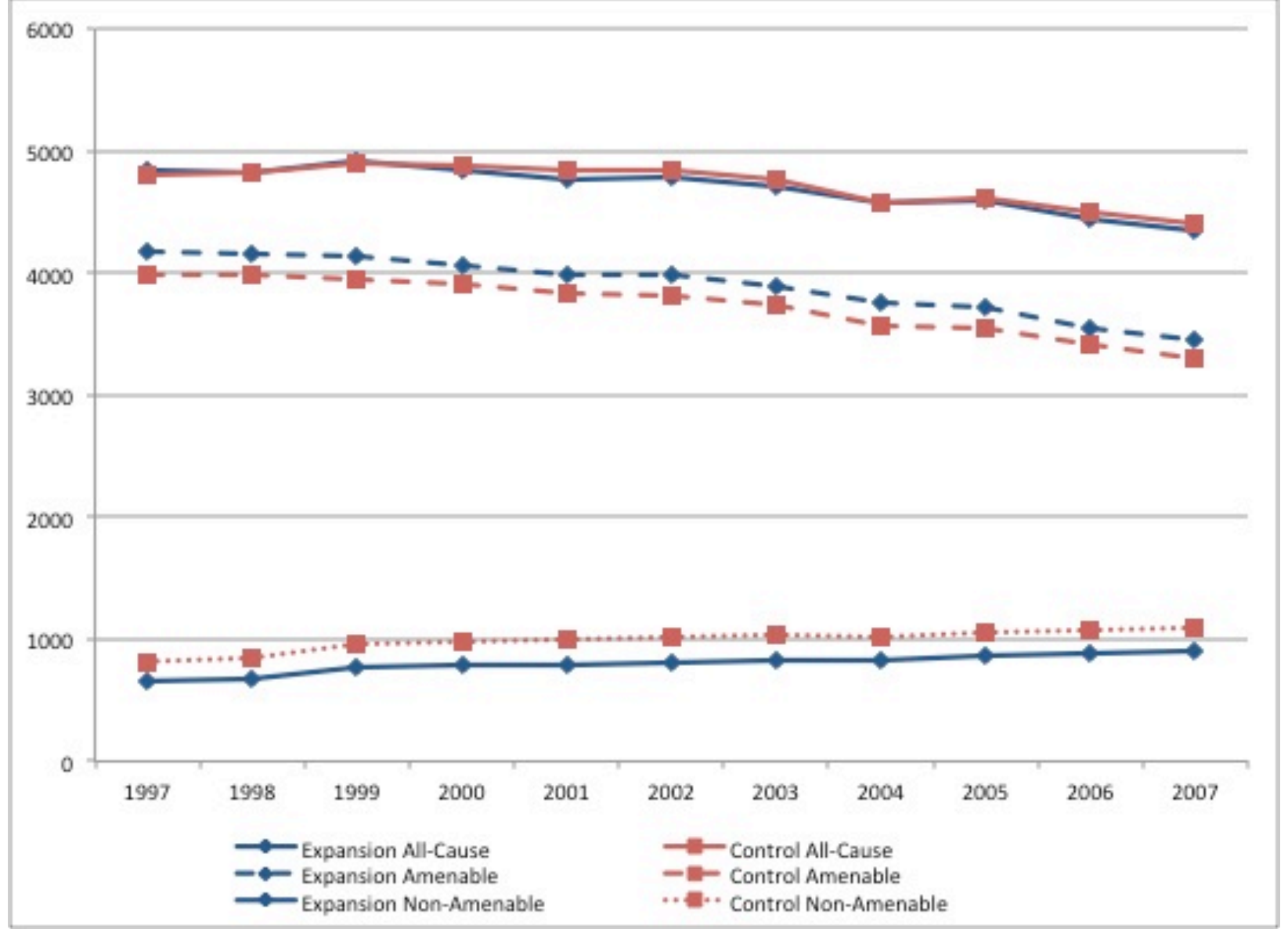

Note: "Non-Amenable" causes of death are those not included in the category "Healthcare Amenable." However, this does not mean they cannot be impacted by health insurance, only that these death rates are likely to be less responsive to insurance coverage than other causes. 